Article

\title{
Retrieving Rain Drop Size Distribution Moments from GPM Dual-Frequency Precipitation Radar
}

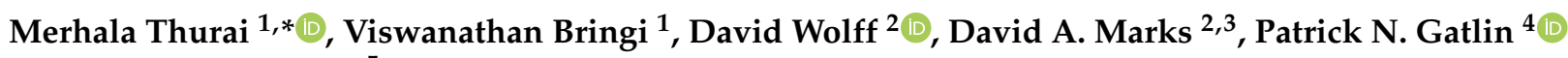 \\ and Matthew T. Wingo ${ }^{5}$ \\ 1 Department of Electrical and Computer Engineering, Colorado State University, Fort Collins, CO 80523, USA; \\ bringi@engr.colostate.edu \\ 2 NASA GSFC Wallops Flight Facility, Wallops Island, VA 23337, USA; david.b.wolff@nasa.gov (D.W.); \\ david.a.marks@nasa.gov (D.A.M.) \\ 3 Science Systems and Applications, Inc., Lanham, MD 20706, USA \\ 4 NASA Marshall Space Flight Center, Huntsville, AL 35808, USA; patrick.gatlin@nasa.gov \\ 5 Earth System Science Center, University of Alabama in Huntsville, Huntsville, AL 35899, USA; \\ wingo@nsstc.uah.edu \\ * Correspondence: merhala@engr.colostate.edu; Tel.: +1-970-491-7678
}

check for updates

Citation: Thurai, M.; Bringi, V.; Wolff, D.; Marks, D.A.; Gatlin, P.N.; Wingo, M.T. Retrieving Rain Drop Size Distribution Moments from GPM Dual-Frequency Precipitation Radar. Remote Sens. 2021, 13, 4690. https://doi.org/10.3390/rs13224690

Academic Editors: Kenji Nakamura, Atsushi Hamada, Mikiko Fujita and Jungho Kim

Received: 8 October 2021

Accepted: 18 November 2021

Published: 20 November 2021

Publisher's Note: MDPI stays neutral with regard to jurisdictional claims in published maps and institutional affiliations.

Copyright: (c) 2021 by the authors. Licensee MDPI, Basel, Switzerland. This article is an open access article distributed under the terms and conditions of the Creative Commons Attribution (CC BY) license (https:/ / creativecommons.org/licenses/by/ $4.0 /)$.

\begin{abstract}
A novel method for retrieving the moments of rain drop size distribution (DSD) from the dual-frequency precipitation radar (DPR) onboard the global precipitation mission satellite (GPM) is presented. The method involves the estimation of two chosen reference moments from two specific DPR products, namely the attenuation-corrected Ku-band radar reflectivity and (if made available) the specific attenuation at Ka-band. The reference moments are then combined with a function representing the underlying shape of the DSD based on the generalized gamma model. Simulations are performed to quantify the algorithm errors. The performance of methodology is assessed with two GPM-DPR overpass cases over disdrometer sites, one in Huntsville, Alabama and one in Delmarva peninsula, Virginia, both in the US. Results are promising and indicate that it is feasible to estimate DSD moments directly from DPR-based quantities.
\end{abstract}

Keywords: raindrop size distributions; retrieval of moments; dual-frequency precipitation radar; global precipitation mission

\section{Introduction}

The global precipitation measurement (GPM) core satellite hosts the dual-frequency precipitation radar (DPR), which is the first spaceborne radar operating at $\mathrm{Ku}$ - and $\mathrm{Ka}$ bands for precipitation mapping [1]. The dual-frequency radar measurements [2] provide a more complete depiction of precipitation globally ( \pm 65 degree latitude; $[3,4])$. The DPR also facilitates better estimates of the two main parameters governing the drop size distributions (DSDs), namely the mass-weighted mean diameter $\left(D_{m}\right)$ and the normalized intercept parameter $\left(\mathrm{N}_{W}\right)$ [5,6]. The DPR precipitation retrieval algorithm [7] employs the normalized representation of the drop size distribution based on the gamma distribution with shape parameter fixed $(\mu=3)$ and uses a rather complex adjustment parameter to estimate the DSD and precipitation rate [8].

A number of recent studies have analyzed the statistics of $\left[D_{m}, N_{W}\right]$ from the DPR and compared these with similar statistics from a diverse network of ground-based polarimetric radars [9] and surface disdrometers on a seasonal or global scale [10,11]. On the global scale, the higher rain rate $(>8-10 \mathrm{~mm} / \mathrm{h})$ DSD parameters $\left[\mathrm{D}_{\mathrm{m}}, \mathrm{N}_{\mathrm{W}}\right]$ are consistent with disdrometer data from continental convection, deep oceanic convection, and oceanic shallow rain. However, on a seasonal basis, the $\mathrm{N}_{\mathrm{W}}$ estimate is not consistent with disdrometer data [10]. Such statistical comparisons have to encompass many years of data to overcome the "snapshot" view from DPR over a footprint of $5 \mathrm{~km} \times 5 \mathrm{~km}$ versus nearly continuous 
DSD measurements from disdrometers (often termed as "point" measurements). Nevertheless, there is much to be gained from overpasses of the GPM satellite over ground disdrometers, as demonstrated herein using the scaled normalized form of N(D). The caveat is that only low numbers of DPR pixels (the sensitivity limits the reflectivity at $\mathrm{Ku}$ and Ka-bands to $\sim 10 \mathrm{dBZ}$ [12]) are typically available from a single overpass.

Compared to satellite algorithms, dual-frequency ground-based radars have a long history that dates to early 1970s, when S- and X-band radars with matched beams were mounted on the same pedestal to observe precipitation [13]. This seminal article [13] develops an algorithm to estimate the range-resolved specific attenuation at $X$-band using the path integrated attenuation (PIA) as a constraint and a $\mathrm{k}-\mathrm{Z}$ power law, where $\mathrm{Z}$ is the radar reflectivity and $\mathrm{k}$ is the specific attenuation. This algorithm works "backwards" from the last range gate and computes the coefficient of the k-Z power law for each beam assuming a fixed exponent based on DSD scattering simulations. The methodology in [13] is in fact the precursor for many of the radar algorithms developed for TRMM and GPM for attenuation correction [14-16].

The (S, Ka-band) dual-frequencies have been used to retrieve liquid water content using the methodology in [13], e.g., see [17]. The latter reference [17] also introduces the "radar estimated size", which is not dependent on the shape of the DSD; rather, it is the ratio of moments that are closest to $\mathrm{Z}$ and Ka-band attenuation, i.e., $\left(\mathrm{M}_{6} / \mathrm{M}_{3}\right)^{1 / 3}$, where $\mathrm{M}_{6}$ and $\mathrm{M}_{3}$ represent the sixth and the third moments, respectively. It will become obvious later that the concept of radar estimated size is a precursor to the characteristic diameter defined in the generalized scaling-normalization framework of Lee et al. [18] (see Equation (5) further down).

The near-linear relation of rainfall rate, $\mathrm{R}$, with Ka-band specific attenuation, $\mathrm{k}_{\mathrm{Ka}}$, has been clearly described in [19], where they show that $\mathrm{k}_{\mathrm{Ka}}=0.22 \mathrm{R}^{1.04}$, with $\mathrm{k}_{\mathrm{Ka}}$ in $\mathrm{db} / \mathrm{km}$ and $\mathrm{R}$ in $\mathrm{mm} / \mathrm{h}$ from scattering simulations based on a small number $(\sim 200)$ of $1 \mathrm{~min}$ DSDs measured by a Joss-Waldvogel disdrometer in Locarno, Switzerland. The relation is not dependent on temperature of the drops, at least in the range 0 to $18{ }^{\circ} \mathrm{C}$, but the coefficient can change if the mean $\mathrm{D}_{\mathrm{m}}$ of the DSDs used in the fitting is from a different rain climatology. For example, the coefficient is about 30\% smaller if DSDs from marine stratocumulus drizzle (mean $\mathrm{D}_{\mathrm{m}}$ is about $0.2 \mathrm{~mm}$ ) are used in the fit process (not shown here but see Figure 3a,b in [20].

The microphysical processes (warm rain) depend on $M_{0}$ to $M_{3}+b$, where $b$ is the exponent of the fall-speed versus drop diameter, $\mathrm{D}$, relation [21]. The $\mathrm{M}_{0}$ and $\mathrm{M}_{3}$ moments are the prognostic variables in many two-moment bulk microphysical schemes (e.g., [22]), but they are not accurate for predicting polarimetric variables such as the specific differential propagation phase, $K_{d p}\left(M_{4.5}\right)$, and the differential reflectivity, $Z_{D R}\left(M_{7} / M_{6}\right.$ [23]). A three-moment scheme using $\left[\mathrm{M}_{0}, \mathrm{M}_{3}\right.$ and $\left.\mathrm{M}_{6}\right]$ as the prognostic variables was developed by [24], which resulted in substantial improvements (in predicting the spectral shape parameter $\mu$ of the gamma DSD) at the expense of increased complexity and computational resources. Using a very large data base of measured distributions and an even larger data base of DSDs from an explicit 1D simulation, which has all warm rain processes included $[25,26]$, showed that the three-moment combination $\left[\mathrm{M}_{2}, \mathrm{M}_{4}\right.$ and $\left.\mathrm{M}_{6}\right]$ could be used to compute all the other moments $\left[\mathrm{M}_{0}, \mathrm{M}_{1}, \mathrm{M}_{3}, \mathrm{M}_{5}, \mathrm{M}_{7}\right]$ with minimal variance. Their goal was to represent the microphysical processes without invoking a particular form for the shape of the distribution. In a subsequent paper [27], they show that the time derivative (tendency) of any moment could be expressed as the product of power laws of the reference moments. An earlier publication [28] had shown how the tendency of two- and three-moment reference moments could be simplified for some processes such as evaporation and sedimentation when compared with a 1D explicit scheme. They found that $\left[\mathrm{M}_{3}, \mathrm{M}_{6}\right]$ gave the best overall accuracy for the aforementioned processes when compared to an explicit scheme (however, they did not consider collisional processes). Morrison et al. [27], on the other hand, give equations for collisional break-up as well as coalescence (in addition to single-drop processes) but did not explicitly evaluate the 
$\left[\mathrm{M}_{3}, \mathrm{M}_{6}\right]$ two-moment predictions. Thus, it is not clear if $\left[\mathrm{M}_{3}, \mathrm{M}_{6}\right]$ is the "best" choice for the prognostic moments when considering in general all warm rain processes.

The choice of reference moments will be limited to higher orders for both polarimetric and dual-frequency radars. For dual-polarization radar algorithms, the physical basis relies on the correlation between raindrop shape and size, while dual-wavelength weather radar algorithms rely primarily on non-Rayleigh scattering at the shorter wavelength. The equations for estimating parameters of the DSD are nearly identical in the presence of attenuation [29].

Recently, retrieval of DSD moments from ground-based polarimetric radar measurements has been evaluated using X-band data, with special emphasis on the prediction of lower-order moments. Two examples are [30,31]. In both cases, the procedure initially entailed the retrieval of two "reference" moments, in both cases $\left[\mathrm{M}_{3}, \mathrm{M}_{6}\right]$, followed by reconstructing the DSDs and calculating other moments assuming a specific function to represent the underlying shape (denoted $\mathrm{h}(\mathrm{x})$, as explained in the next section). In [30], the two reference moments are estimated using the co-polar reflectivity $\left(Z_{h}\right.$ for horizontal polarization), differential reflectivity $\left(Z_{\mathrm{dr}}\right)$, and the specific differential propagation phase $\left(K_{d p}\right)$, whereas in [31], they are estimated using $Z_{h}, Z_{d r}$, and specific attenuation, $A_{h}$.

In this paper, we examine a conceptually similar approach for retrieving the DSD moments from the DPR products. As with the polarimetric radar retrievals, we first estimate two (chosen) reference moments $\left[\mathrm{M}_{3}, \mathrm{M}_{6}\right]$. Then, using the "most probable" underlying shape function $\mathrm{h}(\mathrm{x})$, we determine other DSD moments. The methodology and concepts are given in Section 2. Section 3 describes the DSD datasets and simulation results to demonstrate which moments are the best reference moments and which DPR-based quantities should be used to estimate those. Parameterization errors are quantified based on "true" versus retrieved moments from our simulation results. In Section 4, we present two GPM-DPR overpass cases and assess the accuracy of the retrievals, but noting an important limitation, namely that one of the quantities needed for our proposed method is not available as an official DPR product. Error sources are considered in Section 5, along with some discussion of results, caveats, and conclusions.

\section{Methodology and Concepts}

The scaling normalization framework of Lee et al. [18] expresses any moment of the DSD (inclusive of the lower order moments, $\mathrm{M}_{0}-\mathrm{M}_{2}$ ) in terms of the product of the power laws of the chosen reference moments and the underlying function $\mathrm{h}(\mathrm{x})$ describing the intrinsic shape of the DSD. The invariance of $h(x)$ has been demonstrated in a number of articles ([32,33] and Figure 2 in [20]). In compact notation, the DSD is expressed as $\mathrm{N}(\mathrm{D})=\mathrm{N}_{0}{ }^{\prime} \mathrm{h}(\mathrm{x})$, where (a) the intrinsic shape of the DSD, $\mathrm{h}(\mathrm{x})$ is a function of $\mathrm{x}$, the scaled diameter $\mathrm{D} / \mathrm{D}_{\mathrm{m}}{ }^{\prime}$, and (b) $\mathrm{N}_{0}{ }^{\prime}$ is the normalized "intercept" parameter (see later in Equations (4) and (5)).

The nth moment, $\mathrm{M}_{\mathrm{n}}$, of the DSD (units are $\mathrm{mm}^{\mathrm{n}} / \mathrm{m}^{3}$ ) is given by:

$$
\mathrm{M}_{\mathrm{n}}=\int_{0}^{\infty} \mathrm{N}(\mathrm{D}) \mathrm{D}^{\mathrm{n}} \mathrm{dD},
$$

where $\mathrm{D}$ is the equi-volume drop diameter, and $\mathrm{N}(\mathrm{D})$ is the drop concentration per unit volume in the diameter interval $\mathrm{D}$ to $\mathrm{D}+\delta \mathrm{D}$. When $\mathrm{n}$ equals zero, i.e., the zeroth moment, $\mathrm{M}_{0}$ will represent the total number of drops per unit volume. In remote sensing applications at microwave frequencies, $M_{3}$ will be related to specific attenuation, and $M_{6}$ will be related to the radar reflectivity, but in the non-Rayleigh scattering region, the relationships will show more scatter depending on the frequency-band.

\subsection{Exponential and Gamma Distributions}

Characterization of the DSD dates back to the 1940s, with one of the most-quoted references being that of Marshall and Palmer [34] who used manual DSD measurements in stratiform rain and used an exponential distribution (with a rainfall intensity-dependent 
slope parameter) to represent their data. Decades later, a three-parameter, un-normalized gamma distribution was introduced [35] to better represent DSD measurements with smaller time intervals. This has been widely used in numerous studies on DSD variability, e.g., [36-39]. Retrievals of DSD parameters, e.g., from polarimetric radar data and from spaceborne radar data, have also assumed the gamma model [40-43]. The model will be referred to as the "standard gamma (SG) model".

\subsection{Double-Moment Normalization and Generalized Gamma Model}

A more novel and sound approach for DSD representation was introduced by SempereTorres et al. [44] and by Testud et al. [5] after several studies had shown that the underlying shape of the DSD can be revealed if $N(D)$ is normalized by the parameter $N_{W}$, the normalized intercept parameter, together with the normalization $D$ by the parameter $D_{m}$, the mass-weighted mean diameter $[5,45]$. Often, the underlying shape is denoted as $\mathrm{h}(\mathrm{x})$ where $\mathrm{x}$ is the so-called "scaled diameter", [46], given by:

$$
\mathrm{x}=\left(\frac{\mathrm{D}}{\mathrm{D}_{\mathrm{m}}^{\prime}}\right),
$$

where $D_{m}{ }^{\prime}$ is defined later in Equation (5).

Further to the scaling law of Sempere-Torres [44] and the scaling normalization of Testud [5], a unified approach was proposed in [18] based on double-moment normalization with any two reference moments, $\left[\mathrm{M}_{\mathrm{i}}, \mathrm{M}_{\mathrm{j}}\right]$, resulting in:

$$
\begin{gathered}
\mathrm{h}(\mathrm{x})=\frac{\mathrm{N}(\mathrm{D})}{\mathrm{N}_{0}^{\prime}} \\
\mathrm{N}_{0}^{\prime}=\mathrm{M}_{\mathrm{i}}^{\frac{(\mathrm{j}+1)}{(j-\mathrm{i})}} \mathrm{M}_{\mathrm{j}}^{\frac{(\mathrm{i}+1)}{(\mathrm{i}-\mathrm{j})}} \\
\mathrm{D}_{\mathrm{m}}^{\prime}=\left(\frac{\mathrm{M}_{\mathrm{j}}}{\mathrm{M}_{\mathrm{i}}}\right)^{\frac{1}{(j-\mathrm{i})}}
\end{gathered}
$$

The choice of the two reference moments will depend on the application.

Lee et al. [18] also considered the use of the so-called 'generalized gamma' (GG) model, which had previously been shown to be applicable and useful for DSD studies in, e.g., [47]. They showed that the GG was far more suitable to represent $h(x)$, since it uses two shape parameters, $\mu_{\mathrm{GG}}$ and $\mathrm{c}$, and as a result, yielded more flexibility. The term $\mathrm{h}(\mathrm{x})$ will then be given by:

$$
\mathrm{h}_{\mathrm{GG}(\mathrm{i}, \mathrm{j}, \mu, \mathrm{c})}(\mathrm{x})=\mathrm{c} \Gamma_{\mathrm{i}}^{\frac{\left(\mathrm{j}+\mathrm{c} \mu_{\mathrm{GG}}\right)}{(i-\mathrm{j})}} \Gamma_{\mathrm{j}}^{\frac{\left(-\mathrm{i}-\mathrm{c} \mu_{\mathrm{GG}}\right)}{(\mathrm{i}-\mathrm{j})}} \mathrm{x}^{\mathrm{c \mu} \mu_{\mathrm{GG}}-1} \exp \left[-\left(\frac{\Gamma_{\mathrm{i}}}{\Gamma_{\mathrm{j}}}\right)^{\frac{\mathrm{c}}{(\mathrm{i}-\mathrm{j})}} \mathrm{x}^{\mathrm{c}}\right]
$$

Combining Equations (3), (4), and (6) and rearranging these, we obtain:

$$
N(D)=M_{i}^{\frac{(j+1)}{(j-i)}} M_{j}^{\frac{(i+1)}{(i-j)}} c \Gamma_{i}^{\frac{\left(j+c \mu_{G G}\right)}{(i-j)}} \Gamma_{j}^{\frac{\left(-i-c \mu_{G G}\right)}{(i-j)}} x^{c \mu_{G G}-1} \exp \left[-\left(\frac{\Gamma_{i}}{\Gamma_{j}}\right)^{\frac{c}{(i-j)}} x^{c}\right]
$$

Equation (7) forms the basis of our analyses presented here. As seen, N(D) is dependent on the two chosen reference moments and the two shape parameters $\mu_{\mathrm{GG}}$ and c. Note also that, if we choose the third and the fourth moments as our reference moments, i.e., set $i=3$ and $j=4$, and further, $c$ is set to 1, then Equation (6) will simplify to the standard gamma model, with the shape parameter (denoted as $\mu_{\mathrm{SG}}$ in this paper). Under these conditions, $\mu_{\mathrm{SG}}=\mu_{\mathrm{GG}}-1$, and further, when $\mu_{\mathrm{GG}}$ is set to 1 , i.e., $\mu_{\mathrm{SG}}=0$, an exponential distribution is obtained. 


\section{Simulations and Datasets}

\subsection{Choice of Reference Moments}

The choice of the two reference moments in Equation (6), as mentioned earlier, depends on the application. For rain microphysical studies, $\mathrm{M}_{3}$ and $\mathrm{M}_{4}$ are often used, whereas for remote sensing applications, $\mathrm{M}_{3}$ and $\mathrm{M}_{6}$ are more commonly used.

Since the moments of rainfall rate, $\mathrm{R}$ and liquid water content, $\mathrm{W}$, are close (i.e., $\mathrm{M}_{3}$ vs. $\mathrm{M}_{3.67}$, e.g., [40]), we can expect a near linear relation between $\mathrm{W}$ and $\mathrm{k}_{\mathrm{Ka}}$. For Rayleigh scattering reflectivity, $Z$ is the sixth moment of the DSD, which is approximately the case for $\mathrm{Ku}$-band. Thus, we have selected $\mathrm{k}_{\mathrm{Ka}}$ for retrieval of $\mathrm{M}_{3}$ and $\mathrm{Z}_{\mathrm{Ku}}$ for $\mathrm{M}_{6}$, i.e., $\left[\mathrm{M}_{3}, \mathrm{M}_{6}\right]$ have been chosen as the reference moments. Although this quantity is currently not available as an official DPR product, it can be 'reproduced' by the DSD parameters that are currently accessible. We now examine these variabilities via scattering simulations using DSD measurements.

\subsection{DSD Data for Simulations}

The DSD data used herein were obtained from three observation campaigns in three different locations, namely (i) Greeley, Colorado, (ii) Huntsville, Alabama, and (iii) Wallops Island, Virginia, three climatically very different locations in the US. They represent semiarid continental climate, a sub-tropical continental climate, and a mid-latitude coastal region, respectively. In all three cases, the DSDs were obtained from (a) Meteorological Particle Spectrometer (MPS; [48]) and (b) 2D video disdrometer (2DVD; [49,50]). While the MPS, with its 50-micron resolution, provided accurate measurements of concentrations of small drops (especially for $\mathrm{D}<1.2 \mathrm{~mm}$ ), the 2DVD provided better measurements for larger drop sizes. In all three locations, the MPS and the 2DVD had been installed within a two-third scaled double wind fence (DFIR; [51]). The overlap of the DSD measurements between the two instruments has been investigated extensively in [52] and found to be reasonably close to within acceptable accuracy in the 0.7 to $1.2 \mathrm{~mm}$ drop diameter range. The composite DSD, which we refer to here as the "full DSD spectra" [53], ranged from $\mathrm{D}=0.15 \mathrm{~mm}$ up to large and very large drops, the maximum recorded in our datasets being $\mathrm{D}=8 \mathrm{~mm}$ in the outer rain-bands of a hurricane event (Dorian) over Wallops site [54]. MPS measurements were used for $\mathrm{D} \leq 0.8 \mathrm{~mm}$ and 2DVD measurements for $\mathrm{D}>0.8 \mathrm{~mm}$.

\subsection{Scattering Simulations}

A total of around $30003 \mathrm{~min}$ DSDs from the three locations were used as input to T-matrix scattering calculations at $\mathrm{Ku}$ and Ka bands. A 20 deg $\mathrm{C}$ temperature was assumed. This computational method uses the spherical vector wave functions for the farfield scattering matrix with unknown expansion coefficients, and the total field inside the dielectric is also expanded the same way. The incident wave is also expanded in the same way but with known coefficients. The extended boundary condition is the main principle whereby the surface electric and magnetic currents on the dielectric radiate the negative of the incident field throughout the particle and the far field scattered external to the minimum sphere containing the particle. Thus, the far field expansion coefficients and the incident field are cast into a matrix called the transition matrix (T-matrix), which depends on the dielectric shape (must have an axis of rotational symmetry) and the dielectric constant. The method is very fast compared to the method of moments, which use patch elements (a large number compared to the entire basis functions used in the T-matrix). A comprehensive review of this method can be found in [55].

The computed radar reflectivity $(\mathrm{Z}, \mathrm{dBZ})$ and the specific attenuation $(\mathrm{k})$, together with the DSD moments (from $\mathrm{M}_{0}$ to $\mathrm{M}_{7}$ ), showed that the best estimates (i.e., with the lowest uncertainties) for $\left[\mathrm{M}_{6}\right.$ and $\left.\mathrm{M}_{3}\right]$ were $\mathrm{Z}_{\mathrm{Ku}}$ and $\mathrm{k}_{\mathrm{Ka}}$, respectively. The results are shown in Figure $1 \mathrm{a}, \mathrm{b}$ as color-contoured frequency of occurrence (2D) plots. Panel (a) shows very little scatter, indicating that the uncertainties associated with the estimation of $\mathrm{M}_{6}$ will be very little, whereas panel (b) shows somewhat more significant scatter, indicating the 
uncertainties in $\mathrm{M}_{3}$ estimation will be somewhat larger. Note, however, that the color scale of number $\mathrm{N}$ in Figure 1 is on a $\log _{10}$ scale.
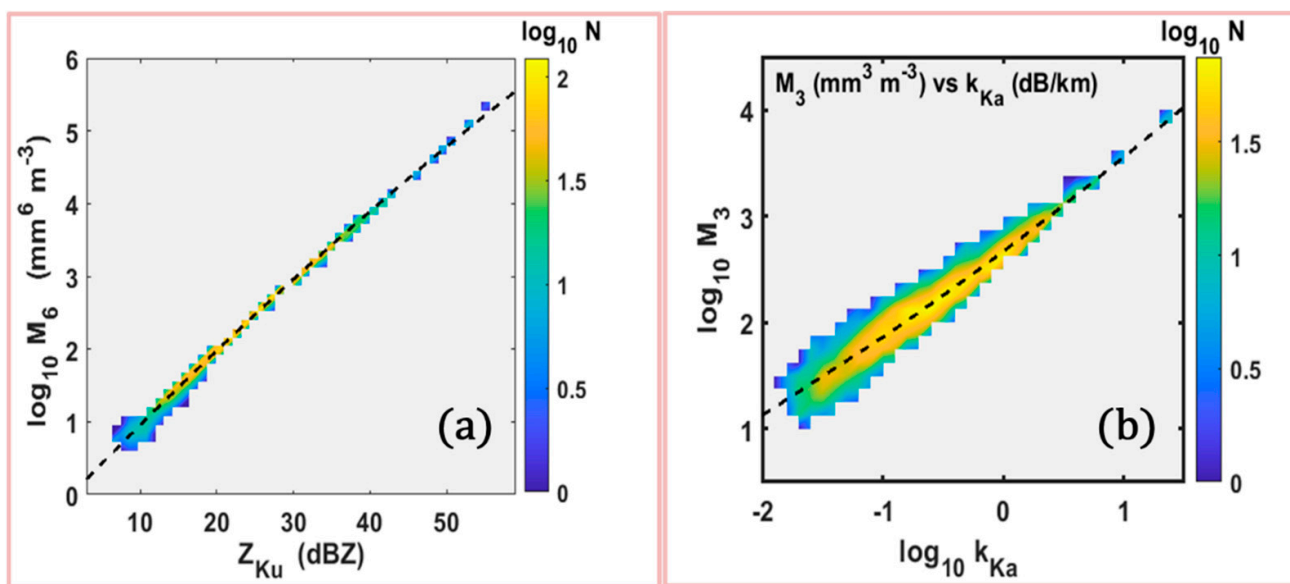

Figure 1. (a) $\log _{10}\left(\mathrm{M}_{6}\right)$ versus $\mathrm{Z}_{\mathrm{Ku}}$ and (b) $\log _{10} \mathrm{M}_{3}$ versus $\mathrm{k}_{\mathrm{Ka}}$ from simulations where the color scales represent the number of occurrences on a log scale. The dashed lines represent the fitted Equations (7) and (8).

The dashed lines in Figure 1a,b represent the fitted equations based on second-order polynomial equations:

$$
\begin{gathered}
\log _{10}\left(\mathrm{M}_{6}\right)=\mathrm{a}_{0}+\left(\mathrm{a}_{1} \mathrm{Z}_{\mathrm{ku}}\right)+\left(\mathrm{a}_{2} \mathrm{Z}_{\mathrm{ku}}^{2}\right) \\
\log _{10}\left(\mathrm{M}_{3}\right)=\mathrm{b}_{0}+\left(\mathrm{b}_{1} \log _{10} \mathrm{k}_{\mathrm{Ka}}\right)+\left(\mathrm{b}_{2}\left[\log _{10} \mathrm{k}_{\mathrm{Ka}}\right]^{2}\right)
\end{gathered}
$$

where $Z_{k u}$ is in dBZ units in Equation (8a). The fitted coefficients and their standard errors are given in Table 1.

Table 1. The fitted coefficients to Equations (7) and (8) and their standard errors.

\begin{tabular}{cccc}
\hline (a) $\log _{10}\left(\mathrm{M}_{6}\right)$ versus $\mathrm{Z}_{\mathrm{ku}}(\mathrm{dBZ})$ & $\mathrm{a}_{0}=-0.114$ & $\mathrm{a}_{1}=0.109$ & $\mathrm{a}_{2}=0.000$ \\
\hline Standard errors for $(\mathrm{a})$ above & $8.07 \times 10^{-3}$ & $6.01 \times 10^{-4}$ & $1.04 \times 10^{-5}$ \\
\hline (b) $\log _{10}\left(\mathrm{M}_{3}\right)$ versus $\log _{10}\left(\mathrm{k}_{\mathrm{Ka}}\right)(\mathrm{dB} / \mathrm{km})$ & $\mathrm{b}_{0}=2.670$ & $\mathrm{~b}_{1}=0.849$ & $\mathrm{~b}_{2}=0.039$ \\
\hline Standard errors for $(\mathrm{b})$ above & $3.58 \times 10^{-3}$ & $5.06 \times 10^{-3}$ & $4.16 \times 10^{-3}$ \\
\hline
\end{tabular}

\subsection{Stability of the Underlying DSD Shape}

Next, we consider the uncertainties associated with the underlying shape of the DSDs using Equations (2)-(4). Figure 2a,b show the double-moment normalization (i.e., $\mathrm{h}(\mathrm{x})$ versus $x$ ) applied to the Greeley (GXY) and the Huntsville (HSV) datasets. In each case, the 25 th, the 50th (median), and the 75th percentile curves are superimposed. The two sets of curves appear to be similar to each other.

Each of the $3 \mathrm{~min}$ DSDs from the GXY and HSV campaigns had been fitted to Equation (6) with $i=3$ and $j=6$ [53]. The fitted $\mu_{G G}$ versus $c$ are shown in panel (c) as a color-intensity plot. $\mu_{\mathrm{GG}}$ shows a narrow range, but the fitted $c$ values range a wider span. Note, once again, that the color scale of $\mathrm{N}$ is on a $\log _{10}$ scale. The maximum value of $\mathrm{N}$ is reached for $\left[\mu_{\mathrm{GG}}, \mathrm{c}\right]=[-0.25,3.67]$. We will use these as the 'most-probable' combination and will substitute these values into Equation (6) for $i=3$ and $j=6$. To test this most-probable $h(x)$, we show in panel $(d)$ the color-intensity plot of $h(x)$ versus $x$ derived from the 3 min DSDs recorded during category-1 Hurricane Dorian (outer bands only) at the Wallops site [56] as well as the most-probable $h(x)$ from the GXY-HSV analyses. The fit appears to be very representative, capturing the 'high-intensity' trend from the DSD data very well. 


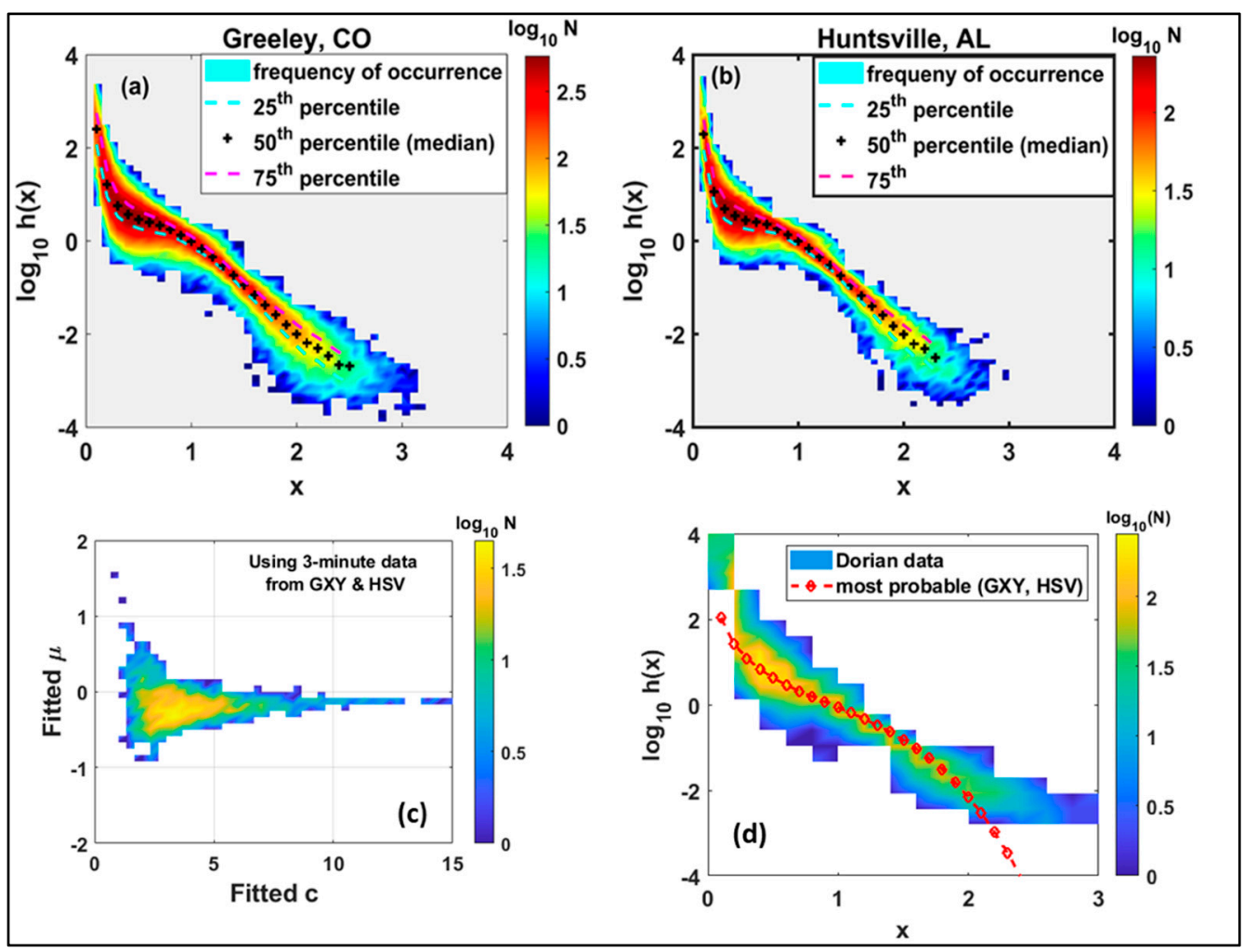

Figure 2. (a) $\log _{10} h(x)$ versus $x$ as intensity color contoured plot from 3 min DSDs from GXY and (b) from HSV and the 25th, 50th (median), and 75th percentile curves overplotted; (c) the fitted values $\left[\mu_{\mathrm{GG}}\right.$ ] versus $\mathrm{c}$ for all the GXY and HSV DSDs combined; (d) $\log _{10} \mathrm{~h}(\mathrm{x})$ versus $\mathrm{x}$ as intensity color contoured plot from 3 min DSDs during the outer-bands of category-1 Hurricane Dorian over Wallops together with the most-probable $h(x)$ versus $x$ constructed from (c).

\subsection{Simulations and Algorithm Errors}

As seen in Sections 3.3 and 3.4, our proposed retrieval method is expected to have uncertainties associated with each of the retrieved moments. To quantify these "algorithm errors", forward simulations and retrievals were performed using the same set of $3 \mathrm{~min}$ DSDs from the three locations. Figure 3 shows the block-diagram for this procedure. The steps can be summarized as follows:

i. $\quad$ Use the $3 \mathrm{~min}$ DSDs for scattering calculations at $\mathrm{Ku}$ and Ka bands;

ii. Use the $Z_{k u}$ and $k_{k a}$ outputs from (i) to estimate $M_{6}$ and $M_{3}$ using Equations (7) and (8);

iii. Retrieve the other moments, viz. $\mathrm{M}_{0}, \mathrm{M}_{1}, \mathrm{M}_{2}, \mathrm{M}_{4}, \mathrm{M}_{5}$, and $\mathrm{M}_{7}$, using the estimated $\left[\mathrm{M}_{3}, \mathrm{M}_{6}\right]$ and $\mathrm{h}(\mathrm{x})$;

iv. Calculate all moments $\left[\mathrm{M}_{0} \ldots \mathrm{M}_{7}\right]$ using the same 3 min DSDs as in (i);

v. Compare (iii) and (iv).

These steps are numbered in red in Figure 3. For step (iii) (with green-box outline), the retrieval of other moments can be achieved analytically using equation (42) of Lee et al. [18]; however, that expression is not valid when $\mu_{\mathrm{GG}}$ is negative, which is the case for our $\mathrm{h}(\mathrm{x})$. An alternate solution is to estimate the other moments numerically by first constructing the full DSD spectra from each of the retrieved $\mathrm{M}_{3}$ and $\mathrm{M}_{6}$ in step (ii) and our $\mathrm{h}(\mathrm{x})$ with $\mathrm{i}=3$ and $\mathrm{j}=4$ for $\mu_{\mathrm{GG}}=-0.25$ and $\mathrm{c}=3.67$ in Equation (7). This is followed by the calculation of other moments using Equation (1).

Results from step (v) are shown in Figure 4 as scatterplots of the retrieved moments versus the 'true' moments, i.e., those derived directly from the $3 \mathrm{~min}$ DSDs. Only the cases with $\mathrm{k}_{\mathrm{Ka}}>1 \mathrm{~dB} / \mathrm{km}$ were chosen. The 1:1 line is included in each plot. The higher-order moments, viz. $M_{3}$ to $M_{7}$ show very good correlation and lie close to the 1:1 line. The lower-order moments, especially $\mathrm{M}_{0}$, show more scatter. The errors are quantified in terms 
of the fractional standard error (FSE) in Table 2. They range from nearly $11 \%$ for $\mathrm{M}_{0}$ to just over $3 \%$ for $\mathrm{M}_{7}$, gradually decreasing. These values represent the overall algorithm errors of the retrieval method.

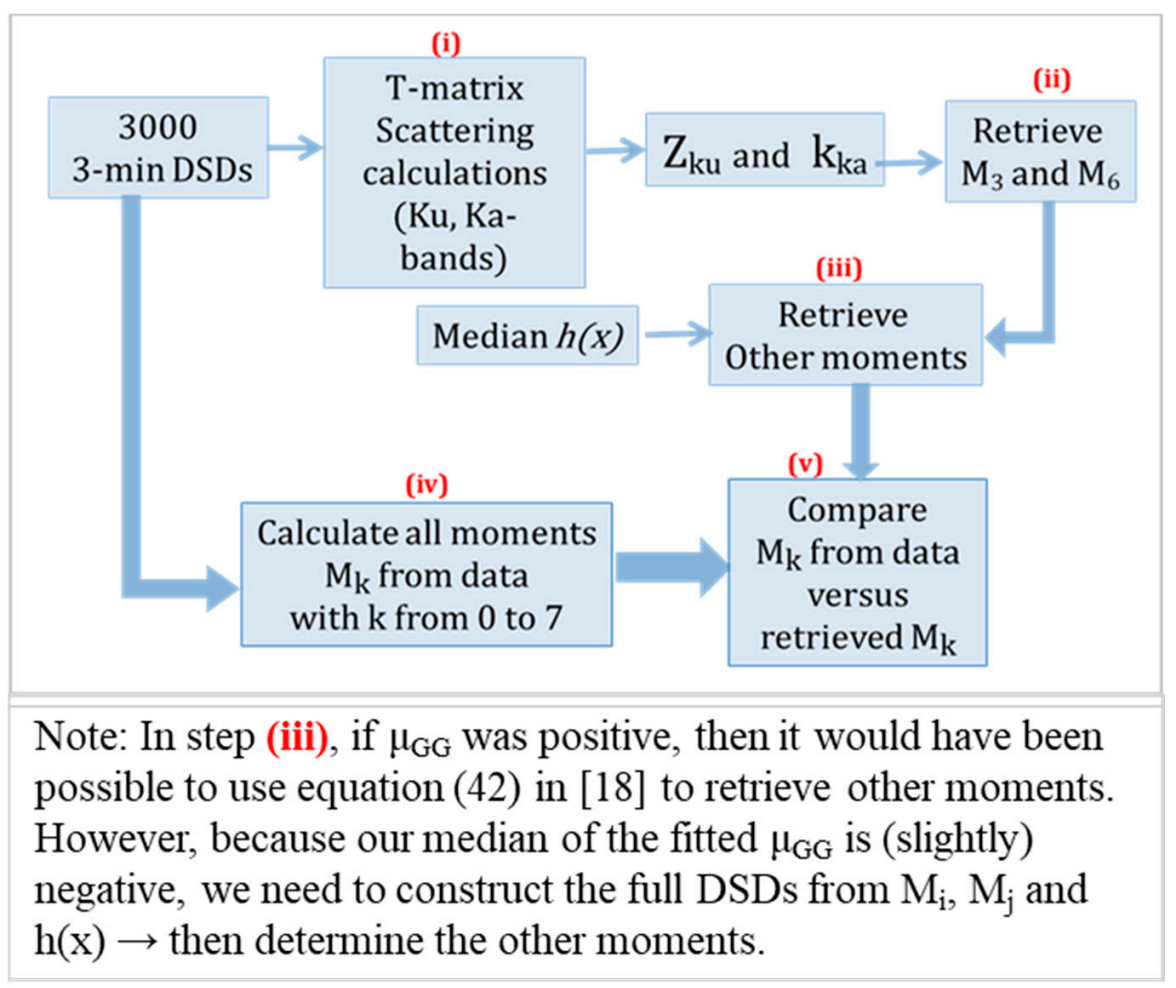

Figure 3. Block diagram outlining the simulation procedure (top), and a comment regarding step (iii) in (bottom).

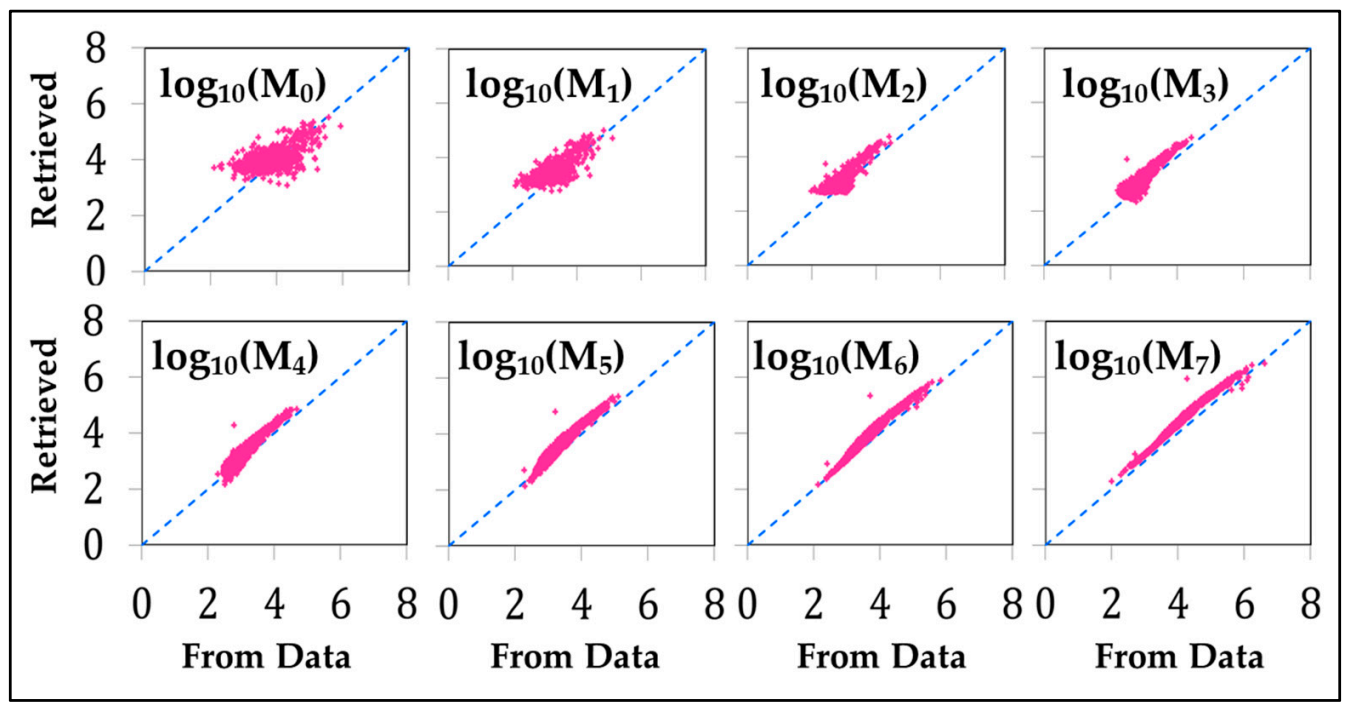

Figure 4. Retrieved moments vs. those directly from the data, i.e., output of step (v) in Figure 3.

Table 2. Fractional standard errors for the retrieval moments.

\begin{tabular}{lcccccccc}
\hline Moment & $\mathbf{M}_{\mathbf{0}}$ & $\mathbf{M}_{\mathbf{1}}$ & $\mathbf{M}_{\mathbf{2}}$ & $\mathbf{M}_{\mathbf{3}}$ & $\mathbf{M}_{\mathbf{4}}$ & $\mathbf{M}_{\mathbf{5}}$ & $\mathbf{M}_{\mathbf{6}}$ & $\mathbf{M}_{\mathbf{7}}$ \\
\hline FSE (\%) & 10.8 & 9.2 & 6.6 & 6.5 & 6.0 & 5.0 & 4.1 & 3.3 \\
\hline
\end{tabular}


Algorithm errors are sometimes referred to as parameterization errors. Bringi et al. [31] considered an additional source of uncertainty, namely those due to radar measurement errors. They found that, for lower-order moments, the parameterization error dominates the overall uncertainties, whereas the radar-measurement errors dominate those for higher-order moments. Although their analyses were related to retrieval of moments from polarimetric radar data, the same trend is likely to apply for the DPR-based retrievals also. Next, we preform basic tests for our retrieval method for two GPM-DPR overpass cases.

\section{GPM-DPR Overpass Cases}

\subsection{The Huntsville Event}

The first of the two events considered here occurred over the Huntsville site, where the MPS and two 2DVDs had been installed ([53]; see also Section 3.2 earlier). It consisted of precipitation associated with a semi-organized line-convection on 11 April 2016, which moved across northern Alabama from $\sim 17$ to $24 \mathrm{~h}$ UTC. The line convection did not directly pass over the disdrometer site; instead, it was approximately $10 \mathrm{~km}$ to the west. The GPM-DPR overpass over the site occurred at 23:31 UTC.

The near-surface DPR products include measured and attenuation-corrected radar reflectivities both at $\mathrm{Ka}$ and $\mathrm{Ku}$ bands as well as $\mathrm{N}_{\mathrm{W}}$ and $\mathrm{D}_{\mathrm{m}}$ for each of the $4 \mathrm{~km}$ by $4 \mathrm{~km}$ radar pixels. The two quantities needed for our retrievals, as mentioned earlier, are the $\mathrm{Ku}$-band radar reflectivity and the specific attenuation at Ka-band. The former is a 'direct' product, but of course, $Z_{\mathrm{Ku}}$ should be the reflectivity values after attenuation-correction is used. The latter, however, is not readily available, but on the other hand, it can be recreated by (i) utilizing $N_{w}$ and $D_{m}$ to derive the DSDs for each pixel, assuming the DPR assumption of standard gamma model with $\mu=3$, followed by (ii) T-matrix calculations to derive $\mathrm{k}_{\mathrm{Ka}}$ for each of the DSDs. These are shown in panels (a) and (b) in Figure 5. In each panel, the color scale is included. The diamonds represent the location of the disdrometers in terms of latitude and longitude. $\mathrm{Z}_{\mathrm{ku}}$ (attenuation-corrected) over the site was $34.6 \mathrm{dBZ}$, and $\mathrm{k}_{\mathrm{Ka}}$ was $0.60 \mathrm{~dB} / \mathrm{km}$. The estimated $\mathrm{M}_{6}$ and $\mathrm{M}_{3}$ are shown in panels (c) and (d), respectively. The color scales (included within each panel) show the $\log _{10}$ of the moments. Using these two moments, together with the $\mathrm{h}(\mathrm{x})$ in Equation (6), the DSDs per pixel were derived, and the other moments, $\mathrm{M}_{0}, \mathrm{M}_{1}, \mathrm{M}_{2}, \mathrm{M}_{4}, \mathrm{M}_{5}$, and $\mathrm{M}_{7}$, were estimated. Four are shown in Figure 6.

Validation of the retrieved moments is not straightforward, but in Table 3, we show the mean and standard deviation of all moments $\mathrm{M}_{0}$ to $\mathrm{M}_{7}$ derived from the DPR data in (22) pixels over and surrounding the disdrometer site, which are compared with those derived directly from the (20) 3 min DSD within \pm 30 min time interval around the DPR overpass.

Table 3. Mean and standard deviations of moments from DPR and DSDs on a $\log _{10}$ scale (units are $\mathrm{mm}^{\mathrm{n}} / \mathrm{m}^{3}$ for $\mathrm{nth}$ moment) and the percentage errors.

\begin{tabular}{cccccc}
\hline Moment & Mean (DPR) & Std. Dev. (DPR) & Mean (DSD) & Std. Dev. (DSD) & Error (\%) \\
\hline $\mathrm{M}_{0}$ & 3.41 & 3.13 & 3.37 & 2.98 & 1.2 \\
\hline $\mathrm{M}_{1}$ & 2.97 & 2.69 & 2.69 & 2.10 & 10.7 \\
\hline $\mathrm{M}_{2}$ & 2.77 & 2.51 & 2.39 & 1.62 & 15.9 \\
\hline $\mathrm{M}_{3}$ & 2.82 & 2.60 & 2.43 & 1.74 & 15.9 \\
\hline $\mathrm{M}_{4}$ & 3.03 & 2.86 & 2.62 & 2.12 & 15.6 \\
\hline $\mathrm{M}_{5}$ & 3.32 & 3.20 & 2.89 & 2.56 & 15.1 \\
\hline $\mathrm{M}_{6}$ & 3.67 & 3.58 & 3.22 & 3.03 & 14.0 \\
\hline $\mathrm{M}_{7}$ & 4.05 & 4.00 & 3.60 & 3.51 & 12.5 \\
\hline
\end{tabular}

Errors are calculated using the $\log _{10}$ of the mean values. 


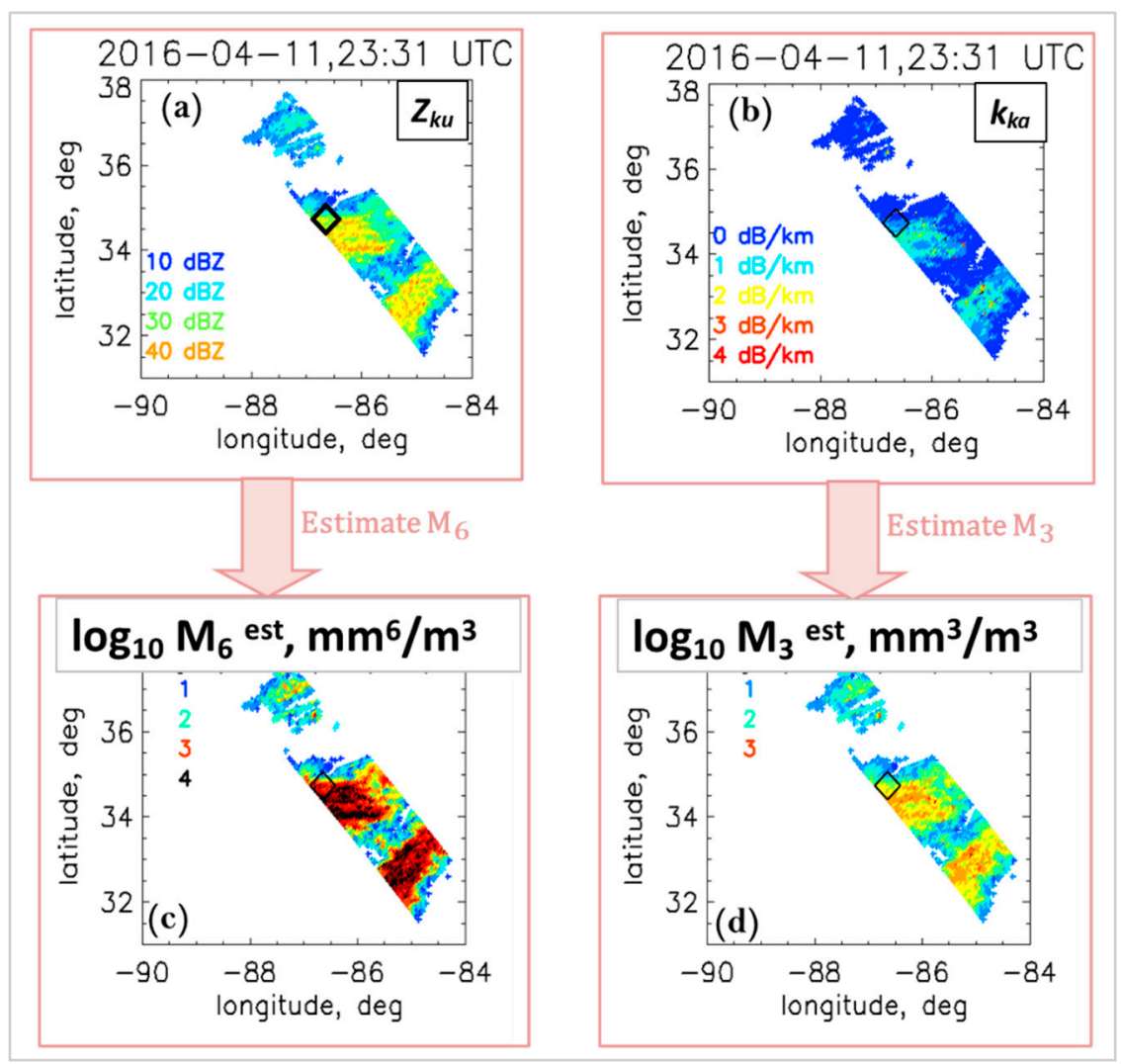

Figure 5. DPR overpass over Huntsville on 11 April 2016 at 23:31 UTC. (a) Attenuation corrected $\mathrm{Z}_{\mathrm{Ku}}$; (b) Ka-band specific attenuation; (c) Estimated $\log _{10}\left(\mathrm{M}_{6}\right)$ from (a); (d) Estimated $\log _{10}\left(\mathrm{M}_{3}\right)$ from $(b)$. Black diamonds indicate the disdrometer location.

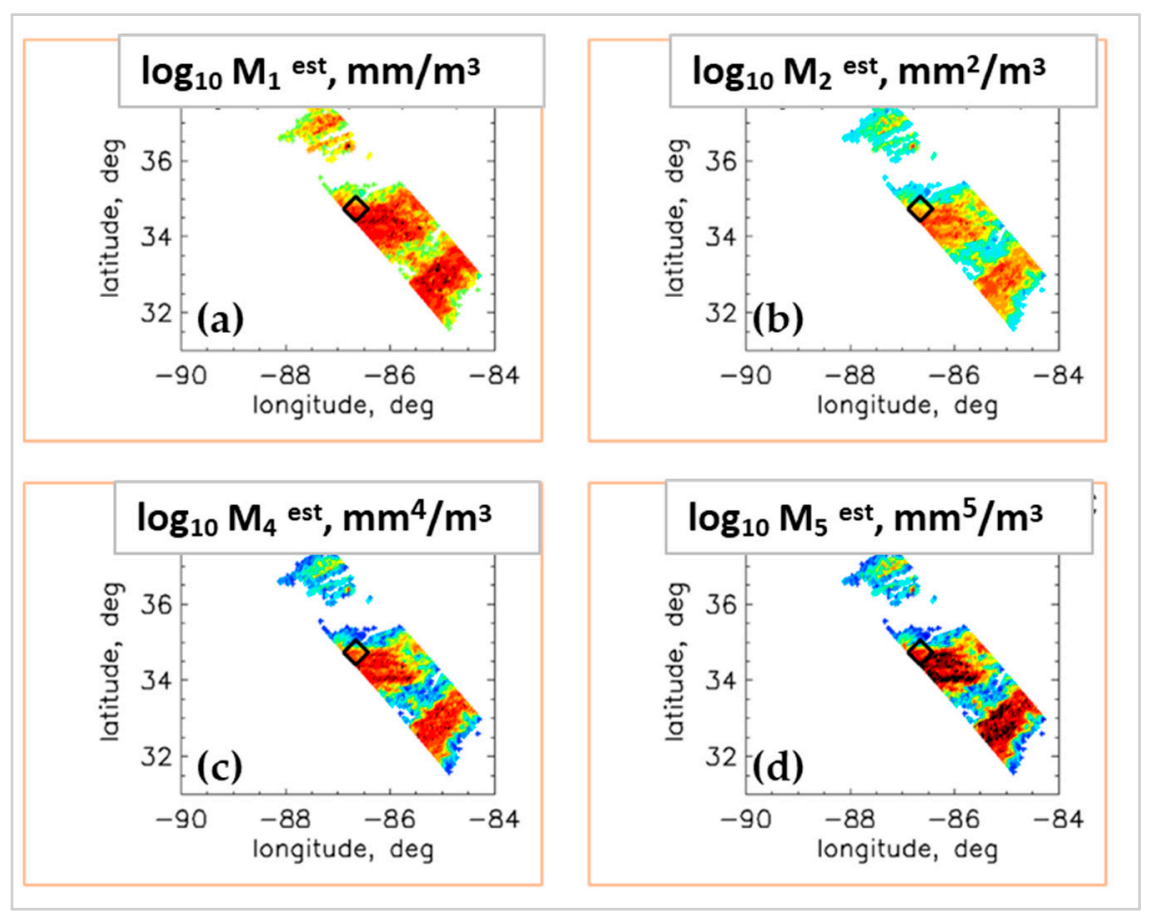

Figure 6. Examples of other retrieved moments for the 11 April 2016 case. (a) $\log _{10}\left(\mathrm{M}_{1}\right)$; (b) $\log _{10}\left(\mathrm{M}_{2}\right)$; (c) $\log _{10}\left(\mathrm{M}_{4}\right)$; (d) $\log _{10}\left(\mathrm{M}_{5}\right)$. Black Diamonds indicate the disdrometer location. The colors are the same as Figure 5. 
From Table 3, we observe the following:

i. Overall good agreement between the two sets of mean values, especially for the zeroth moment.

ii. However, the DSD-based moments show somewhat lower mean values that the DPR-retrieved moments; although, when the standard deviations are included, the overlaps are considerable.

iii. In both cases, $\mathrm{M}_{2}$ shows the lowest mean values and $\mathrm{M}_{7}$ the highest; the standard deviations also show a similar trend.

Furthermore, values of $\mathrm{D}_{\mathrm{m}}$, given by the ratio of the fourth moment to the third ranged from 0.9 to $1.8 \mathrm{~mm}$ for the DPR-based retrievals and 1.1 to $1.8 \mathrm{~mm}$ for the DSD-based estimates. The mean was $1.5 \mathrm{~mm}$ for both cases. Hence, it is likely that our retrievals of moments represent the 'true' values over the $4 \mathrm{~km}$ by $4 \mathrm{~km}$ pixel areas. Further comparisons are given in Appendix A.

\subsection{Remnants of Storm Sally}

The second event we consider in this paper is the remnants of Hurricane Sally over the Wallops area. This storm made landfall in the southern part of the US as category-1 hurricane but weakened considerably as it headed north-east. Remnants of this storm passed over the disdrometer location, and the GPM-DPR overpass occurred north of the site on 18 September 2020 at 04:40 UTC. The closest approach for the nadir beam was around $170 \mathrm{~km} \mathrm{NE}$ of the disdrometer site, but the closest off-nadir beam was around $65 \mathrm{~km}$ north-east. Panel (a) in Figure 7 shows the (near-surface) attenuation-corrected $\mathrm{Z}_{\mathrm{Ku}}$, and panel (b) shows $\mathrm{k}_{\mathrm{Ka}}$. The retrieved $\mathrm{M}_{6}$ and $\mathrm{M}_{3}$ are shown in panels (c) and (d), respectively. These two moments were combined, as was done in the first event, with our most-probable $\mathrm{h}(\mathrm{x})$ to derive other moments. Two examples, namely $\mathrm{M}_{0}$ and $\mathrm{M}_{4}$, are shown in panels (e) and (f), respectively. Note the high $\mathrm{M}_{0}$ values in some regions, indicating high number concentrations.

Direct validation of the retrieved moments is, once again, not possible, especially because the DPR did not directly go over the disdrometer site, but in Figure 8, we compare the histograms of $\left[\mathrm{M}_{0} \ldots \mathrm{M}_{7}\right]$ from DPR and the DSDs. For the latter, $\pm 4 \mathrm{~h}$ around the DPR overpass time was used, whereas for the former, only the data shown in Figure 7 were used (a total of 3269 pixels). There seems considerable overlap in the two sets of histograms in all panels, but the DPR-based moments generally appear to be somewhat higher. On the other hand, if we restrict the DSD-based moment calculations to within $2 \mathrm{~h}$ of the DPR overpass, improvements in the agreement were observed. The green circle in each panel of Figure 8 represents the averaged value from the DSD data within the $2 \mathrm{~h}$ interval. They correspond very well to the mode of the DPR-based histograms.

\subsection{Evaluation of DSD Parameters}

The two main DSD parameters often used in the radar retrievals are $\mathrm{N}_{\mathrm{W}}$ and $\mathrm{D}_{\mathrm{m}}$. There is also another parameter, namely the standard deviation of mass-spectrum, denoted as $\sigma_{M}[37]$, considered useful for rain microphysics studies. While the first two parameters can be defined in terms of the third and the fourth moments, the third parameter additionally requires the fifth moment. The following equations can be derived:

$$
\begin{gathered}
\mathrm{D}_{\mathrm{m}}=\left(\frac{\mathrm{M}_{4}}{\mathrm{M}_{3}}\right) ; \\
\mathrm{N}_{\mathrm{W}}=\frac{4^{4}}{6} \frac{\mathrm{M}_{3}{ }^{5}}{\mathrm{M}_{4}^{4}} \\
\sigma_{\mathrm{M}}=\mathrm{D}_{\mathrm{m}}\left[\frac{\mathrm{M}_{5}-\left(2 \mathrm{D}_{\mathrm{m}} \mathrm{M}_{4}\right)+\left(\mathrm{D}_{\mathrm{m}}{ }^{2} \mathrm{M}_{3}\right)}{\left(\mathrm{D}_{\mathrm{m}}{ }^{2} \mathrm{M}_{3}\right)}\right]^{\frac{1}{2}}
\end{gathered}
$$


Note, however, that Equation (11) is only valid for $\mu_{\mathrm{GG}}>0$. For negative values, it is more appropriate to derive $\sigma_{\mathrm{M}}$ from the DSDs constructed using the two reference moments and the most-probable $\mathrm{h}(\mathrm{x})$.

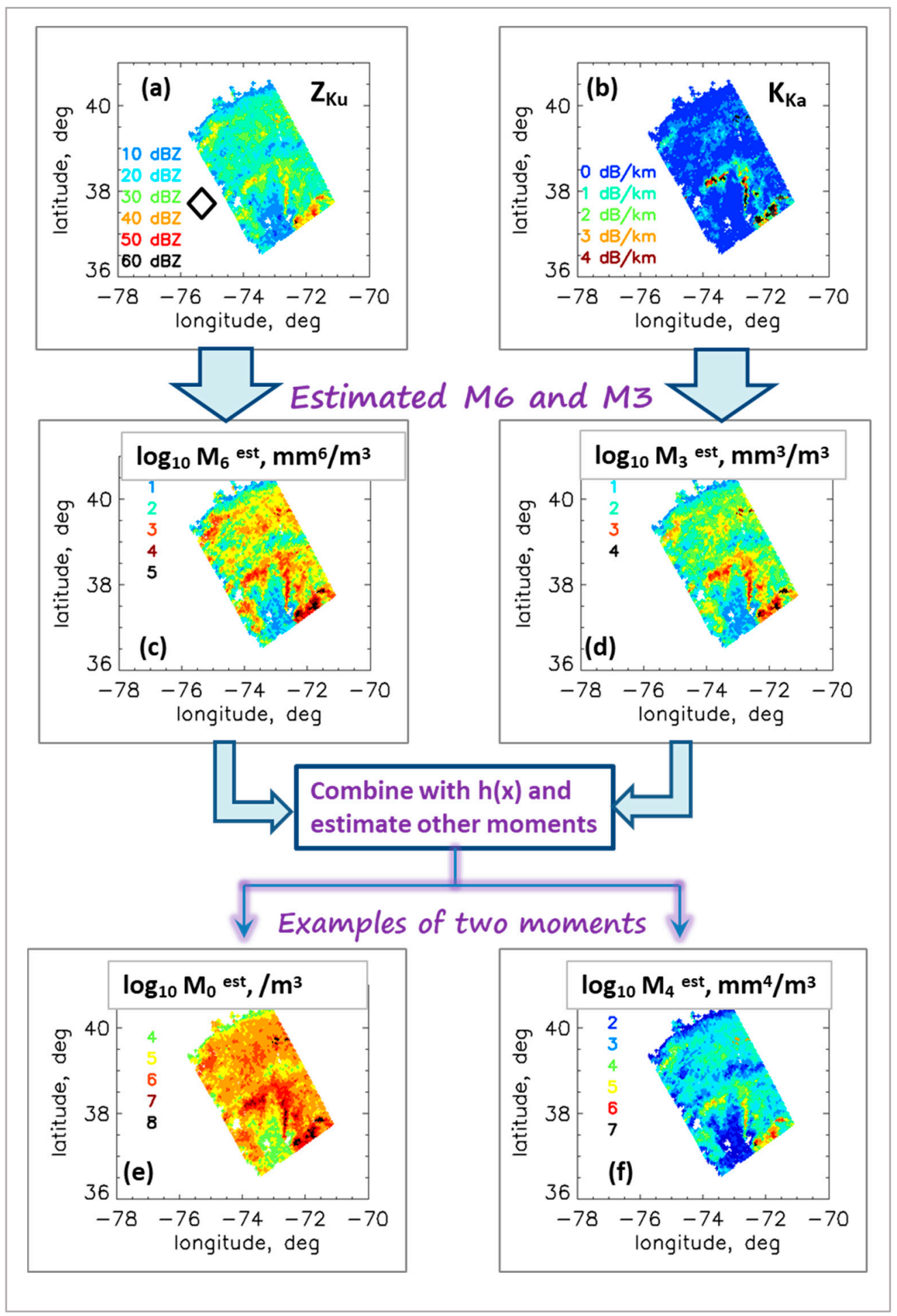

Figure 7. DPR overpass over Wallops during remnants of storm Sally. (a) Attenuation corrected $\mathrm{Z}_{\mathrm{Ku}}$; (b) Ka-band Specific Attenuation; (c) Estimated $\log _{10}\left(\mathrm{M}_{6}\right)$ from (a); (d) Estimated $\log _{10}\left(\mathrm{M}_{3}\right)$ from (b); (e) Estimated $\log _{10}\left(\mathrm{M}_{0}\right)$; (f) Estimated $\log _{10}\left(\mathrm{M}_{4}\right)$. The 'diamond' mark in panel (a) represents the disdrometer site. 


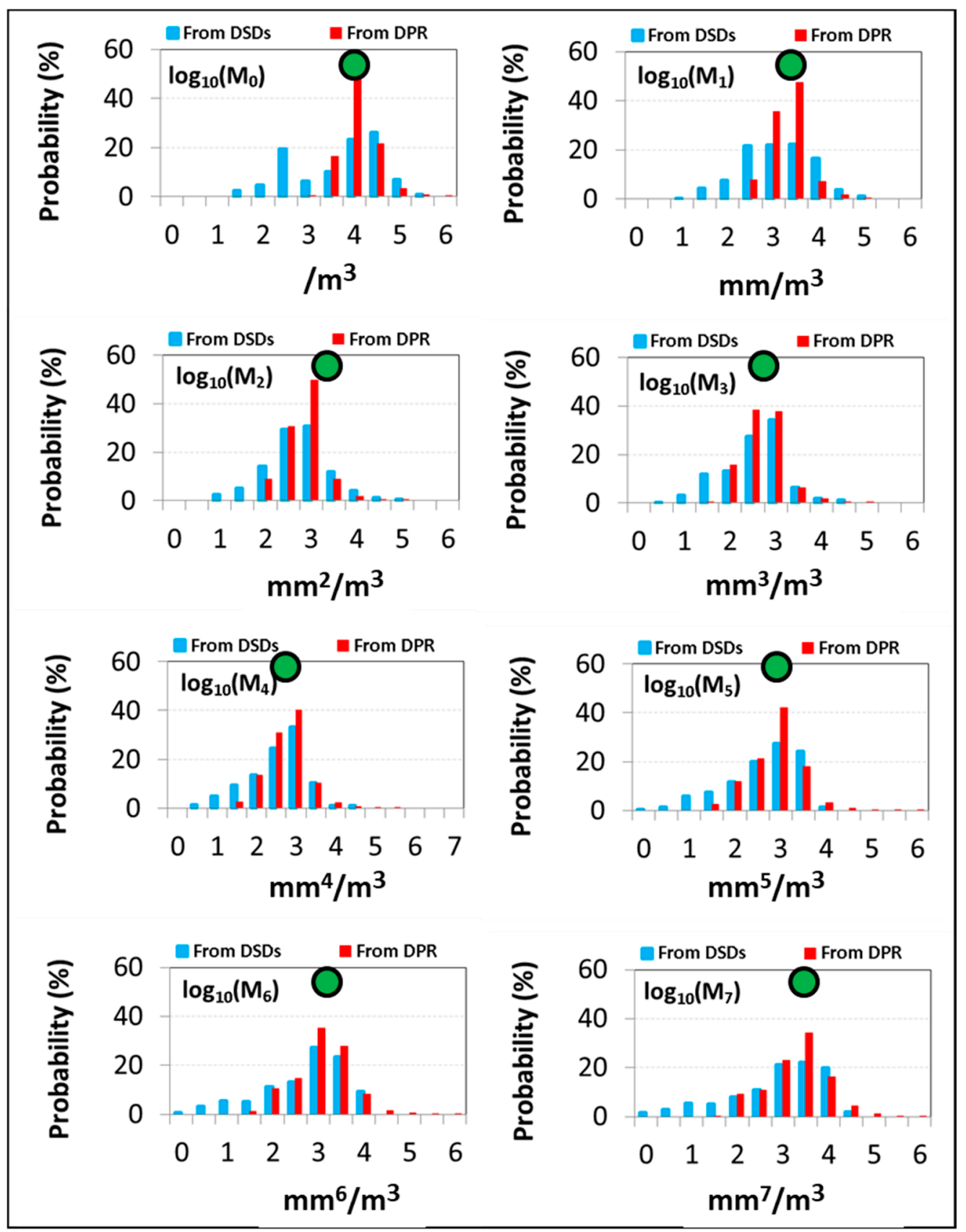

Figure 8. Storm Sally over Wallops area: Comparing histograms of $\log _{10}$ moments from DPRretrieved moments (light red) and DSD based moments (light blue). The green circles represent the average of the DSD-based moments within a $2 \mathrm{~h}$ interval of the DPR overpass.

Figure 9 compares histograms of DPR-retrieved and the DSD-based $D_{m}$ and $\sigma_{M}$. Panel (a) corresponds to the HSV event and panel (b) to storm Sally over Wallops. There are clear differences between the two panels:

i. Remnants of storm Sally shows narrower $\mathrm{D}_{\mathrm{m}}$ histograms (both DPR-retrieved and DSD-based) having lower $D_{m}$ values with a maximum value of only $1.6 \mathrm{~mm}$ whereas the whereas the HSV event shows $D_{\mathrm{m}}$ 's ranging up to $2.1 \mathrm{~mm}$. This is to be expected, because storm Sally originated as a Hurricane, and it is well known that such storms contain an abundance of small drops (higher concentration) compared with other rain regimes $[57,58]$.

ii. The HSV event shows two peaks in the $\mathrm{D}_{\mathrm{m}}$, and these bimodal peaks are evident in both the DPR-retrieved and the DSD-based histograms. It is very plausible that the 
two peaks arise from the (semi-organized) line convection being embedded within a larger widespread (probably stratiform) rain region. The bimodal peaks are also noticeable in the $\sigma_{\mathrm{M}}$ histograms. Storm Sally, on the other hand, shows only one peak in both $\mathrm{D}_{\mathrm{m}}$ and $\sigma_{\mathrm{M}}$.

iii. For the HSV event, there is considerable overlap between the DPR-retrieved and the DSD-based histograms, whereas for storm Sally, the DSD-based histogram has a higher number of cases with lower $D_{m}$ values (i.e., $<0.6 \mathrm{~mm}$ ). This may well be due to the DPR sensitivity, which has a lower limit of approximately $12 \mathrm{dBZ}$ for the radar reflectivity at Ku-band, which, in turn, indicates that light rainfall cases will not be detected often enough. On the other hand, the disdrometer-based DSDs include the MPS measurements with good accuracy for the concentration of small drops.

iv. Another feature that is different between the two panels concerns the proportion of stratiform to convective rain. From the two clear peaks in $D_{m}$ and $\sigma_{M}$ histograms observed in the HSV event (as noted earlier in point (ii)), we can infer that the proportion of the two rain types are somewhat comparable. For storm Sally, by contrast, we have ascertained from NPOL radar quasi-vertical profiles (QVP; [59]) that it was largely stratiform rain. The single peak $D_{m}$ histograms from both DPR and DSD data in panel (b) of Figure 9 support this.

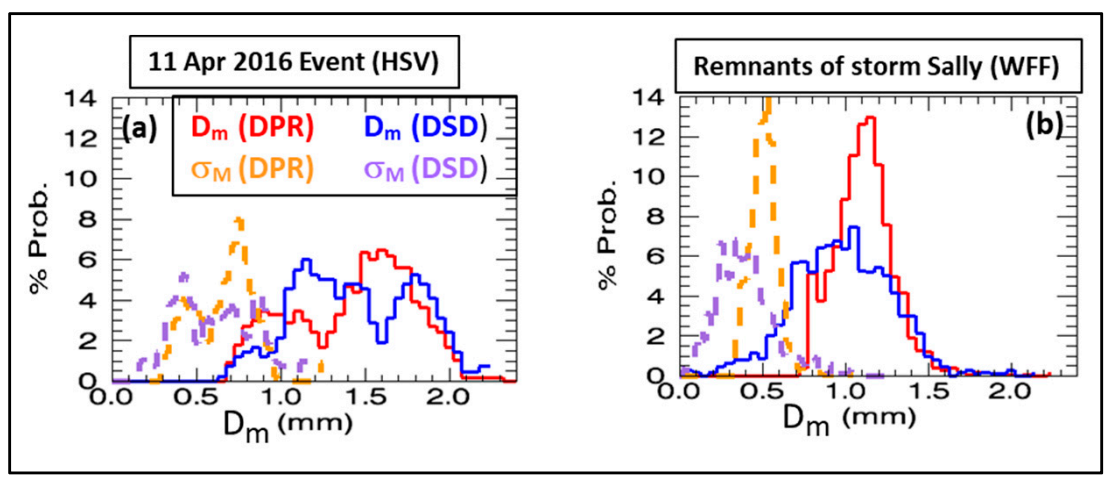

Figure 9. $D_{m}$ and $\sigma_{M}$ histogram comparisons for the two events in Figures 5 and 7 (a,b).

Further improvement in the agreement between DPR and DSD histograms in Figure 9 may be obtained if we restrict the off-nadir angles for the DPR to be less than 10 degrees and/or by utilizing the 'type_Precip' flag product from DPR, in particular, the second digit of the flag. This will be investigated in the near future.

\subsection{Evaluation of (Stratiform and Convective) Rain Types}

Regarding stratiform and convective rain types, it is also of interest to examine the applicability of the classification based on $\mathrm{N}_{\mathrm{w}}$ versus $\mathrm{D}_{\mathrm{m}}$ separation technique. This observational-based empirical method has been used for disdrometer data in the past, and our own recent work has shown that the two rain types can be separated in the $\mathrm{N}_{\mathrm{W}}-\mathrm{D}_{\mathrm{m}}$ space [60-62]. The same method had also been applied to the S-band NPOL radar data and compared with a texture-based method described in [63]. Considerable agreement of over $86 \%$ was obtained [64]. Similar comparisons [65] were made for the C-band CPOL radar based in Darwin, Australia [66].

Disdrometer data represent "point-measurements" (albeit over a 1 or 3 min time interval), and ground-based radar data represent measurements over pulse volumes (but instantaneous). Despite these differences, the stratiform-convective rain separation technique seemed applicable to both. Here, we perform similar tests for the DPR-retrieved $\mathrm{N}_{\mathrm{W}}-\mathrm{D}_{\mathrm{m}}$ for the two cases, noting that the DPR footprint is much larger (4 $\mathrm{km}$ by $4 \mathrm{~km}$ ) than the ground-based radar data. 
The separation technique is based on whether a given pair of $\left[\mathrm{N}_{\mathrm{W}}, \mathrm{D}_{\mathrm{m}}\right]$ lies above or below or specified line. A simple index i given by the following equation is used to quantify the rain-type likelihood $[64,65]$ :

$$
\begin{gathered}
\mathrm{i}=\log _{10}\left(\mathrm{~N}_{\mathrm{W}}^{\mathrm{est}}\right)-\log _{10}\left(\mathrm{~N}_{\mathrm{W}}^{\mathrm{sep}}\right) ; \\
\log _{10}\left(\mathrm{~N}_{\mathrm{W}}^{\mathrm{sep}}\right)=\mathrm{c}_{1} \mathrm{D}_{\mathrm{m}}+\mathrm{c}_{2},
\end{gathered}
$$

where 'sep' corresponds to the separation line, and 'est' represents the estimated value.

Values of $c_{1}$ and $c_{2}$ may be location dependent, but to be consistent with our previous studies, we have used -1.682 and 6.541 , respectively. Broadly speaking, when $i$ is negative, stratiform rain is indicated, and when $\mathrm{i}$ is positive, convective rain is indicated. The pixel-by-pixel DPR-based index value derived for the HSV event is shown in panel (a) of Figure 10. The red color represents i $>0$ (hence, convective rain regions), and the lighter colors indicate $\mathrm{i}<0$ (hence, stratiform rain regions). Panel (b) of Figure 10 shows the path integrated attenuation (PIA) from the matched scan (MS; [7]). The "diamond" symbol indicates the location of the disdrometer site. Positive values of $i$ are seen south-east of the disdrometer site and correlate well, at least visually, with the PIA image in panel (b), i.e., the higher PIA regions correspond to positive index values (red) in panel (a).

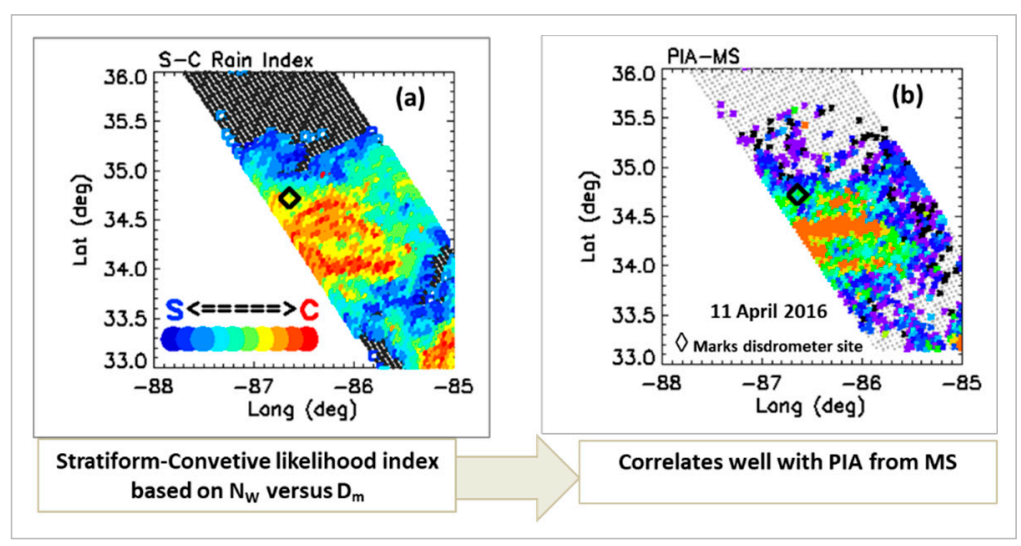

Figure 10. (a) Stratiform (blue) convective (red) rain likelihood index based on the $N_{W}$ versus $D_{m}$ separation method for the 11 April 2016 event in HSV; (b) path-integrated attenuation from the matched scan. The diamond marks the disdrometer site.

Storm Sally, by contrast (as inferred earlier), was mostly stratiform rain when it passed over Wallops. Most of the DPR-retrieved index values (from Figure 7) were negative. Panel (a) of Figure 11 shows the variation of the index values with the PIA from the normal scan (NS; [7]) scan. Only data within a specified range of (off) nadir angles were used. Interestingly, one can see an increase in the i values with PIA. In other words, the $\mathrm{N}_{W}-\mathrm{D}_{\mathrm{m}}$ points move closer to the separation line as the PIA increases, although they lie mostly on the stratiform rain side of the separation line. Panel (b) of Figure 11 shows the QVP plot (a conical scan at 20 deg elevation, height up to $10 \mathrm{~km}$, and range of around $30 \mathrm{~km}$ ) of the radar reflectivity from the S-band NPOL volume scans on 18 September 2020. The clear radar bright-band seen at $4-4.2 \mathrm{~km}$ height throughout the event confirms that the event was dominated by stratiform rain. This validates the predominantly negative i values from panel (c), which were derived from DPR-retrieved $\left[N_{W}, D_{m}\right]$. The increase in i values with PIA in panel (a) is also consistent with another case event analyses using disdrometer data and vertically pointing X-band radar during a cold-rain event in Ontario, Canada (see Section 2 in Thurai et al. 2016), which showed an increase in the (negative values of) $i$ with increasing bright-band thickness. Both the Ontario event analysis and the HSV event in Figure 11a show a very similar trend. 


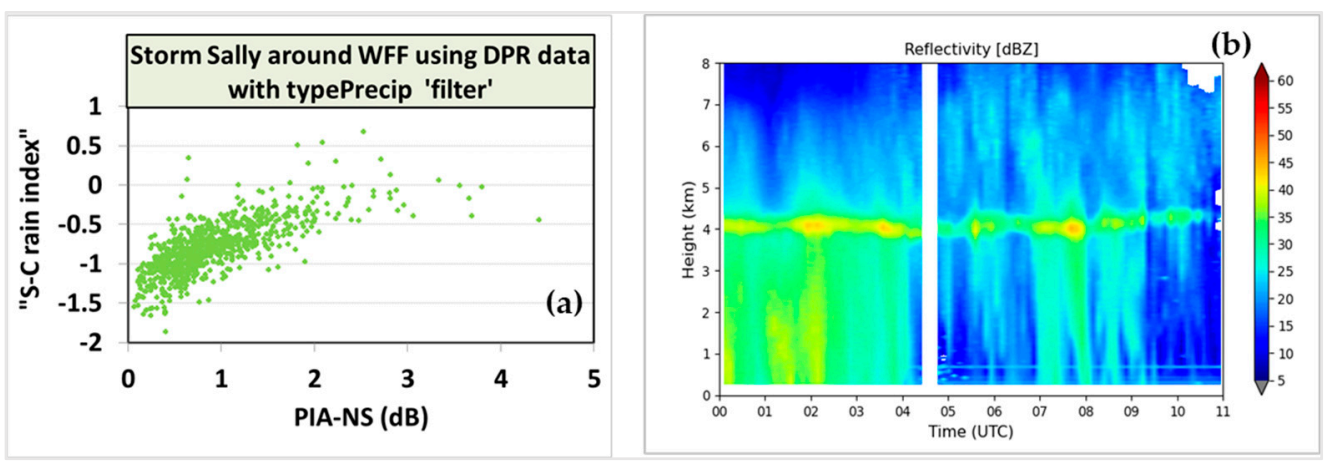

Figure 11. (a) Stratiform-convective likelihood index based on the $N_{W}$ versus $D_{m}$ separation method versus the path-integrated attenuation from the normal scan (PIA-NS) for the remnants of storm Sally in Wallops (note the index values are mostly negative indicating stratiform rain); (b) quasi-vertical profile of reflectivity from NPOL as time variation over the whole event, again indicating stratiform rain, from the $\mathrm{dBZ}$ bright-band in the $4-4.3 \mathrm{~km}$ a.m.s.l. throughout the event.

\section{Summary and Discussion}

Our results have shown that it is feasible to retrieve DSD moments directly from DPR-based quantities. The retrieved moments can act as an initial step, prior to deriving DSD parameters such as $\mathrm{N}_{\mathrm{W}}$ and $\mathrm{D}_{\mathrm{m}}$. Additionally, the DSD moments are very helpful in understanding the microphysical processes involved in various types of rain regimes. The basic premise of this article is that the lower order moments $\left(\mathrm{M}_{0}, \mathrm{M}_{2}, \mathrm{M}_{3}\right)$ of the DSD, which are involved in the formulation of the warm rain process rates (such as evaporation, sedimentation, and binary collisions), can be expressed as products of power laws of the a priori chosen reference moments of higher order $\left(\mathrm{M}_{3}, \mathrm{M}_{6}\right)$ along with moments of $h(x)$, where $h(x)$ is the intrinsic shape of the distribution. The form of $h(x)$ can be any functional shape, provided its moments are finite and positive. The latter formulation also enables estimation of the standard deviation of the mass spectrum $\sigma_{M}$ [67], as well as $N_{W}$ and $D_{m}$.

In our study, the retrieval of moments used only two DPR products, namely the attenuation-corrected radar reflectivity at $\mathrm{Ku}$-band and the specific attenuation at Ka-band. They were used to retrieve the sixth $\left(\mathrm{M}_{6}\right)$ and the third moments $\left(\mathrm{M}_{3}\right)$, respectively. Using these two quantities as our chosen reference moments, and assuming an underlying shape function, $h(x)$, for the DSDs, it is possible to retrieve other moments, ranging from $\mathrm{M}_{0}$ to $\mathrm{M}_{7}$. Note that $\mathrm{h}(\mathrm{x})$ is dependent on the pair of chosen moments, and we have assumed the generalized gamma model to represent $\mathrm{h}(\mathrm{x})$. Using $30003 \mathrm{~min}$ full DSD spectra from two (climatically) different locations, we found that the underlying function corresponding to $\left[\mathrm{M}_{3}, \mathrm{M}_{6}\right]$ pair seemed reasonably stable.

Simulations using the $30003 \mathrm{~min}$ DSDs showed that the algorithm errors for the retrievals would be low; however, for lower-order moments, especially for $\mathrm{M}_{0}$, the errors were found to be more significant. When applying the technique to DPR data, other error sources also need to be considered. They include variance of radar measurement errors and 'point-to-area' variance, which arises from the fact that disdrometer data represent point measurements (although over a $3 \mathrm{~min}$ period), whereas DPR data are over a much larger footprint (although instantaneous), and factors such as non-uniform beam filling also need to be considered. We also need to bear in mind that the DPR has a lower threshold of around $12 \mathrm{dBZ}$ for Ku-band measurements, which will put a lower limit of the estimated $\mathrm{M}_{6}$ used in this method.

Two GPM-DPR overpass cases were used to examine the validity of our retrieval technique, one over the Huntsville site on 11 April 2016 at 23:31 UTC and one over the Wallops site on 18 September 2020 at 04:42 UTC during the passage of remnants of storm Sally. We compared the mean and standard deviation of all moments $\left(\mathrm{M}_{0}\right.$ to $\left.\mathrm{M}_{7}\right)$ derived from the DPR data in pixels in the 0.05 degree of latitude and 0.05 degree longitude around the disdrometer site and compared them with those derived directly from the DSD within 
a 30 min time interval around the DPR overpass. The agreement for all moments (in terms of $\log _{10}$ ) was well within $10 \%$. Furthermore, values of $D_{m}$, given by the ratio of the fourth moment to the third, ranged from 0.9 to $1.8 \mathrm{~mm}$ for the DPR-based retrievals around the disdrometer site and 1.1 to $1.8 \mathrm{~mm}$ for the DSD-based estimates over a $\pm 30 \mathrm{~min}$ period. For the second case, histograms of the moments were derived from DPR and DSDs, and when the DPR-based moments were restricted to areas over and surrounding the disdrometer location, their modes showed very good agreement with the DSD-based mean values, which determined when the disdrometer data were restricted to within $2 \mathrm{~h}$ of the DPR overpass.

$D_{m}$ and $\sigma_{M}$ histograms were also compared for both events. Of the two, remnants of hurricane Sally showed narrower $\mathrm{D}_{\mathrm{m}}$ histograms, both DPR-retrieved and DSD-based, having lower $D_{m}$ values with a maximum value of only $1.6 \mathrm{~mm}$, whereas the HSV event shows $D_{m}$ values ranging up to $2.1 \mathrm{~mm}$. The latter, in fact, showed two peaks in the $\mathrm{D}_{\mathrm{m}}$, and these bimodal peaks are evident in both the DPR-retrieved and the DSD-based histograms. They were attributed to the semi-organized convective line being embedded within a larger widespread (and seemingly stratiform) rain region. The bimodal peaks were also noticeable in the $\sigma_{\mathrm{M}}$ histograms. Sally (around the Wallops disdrometer area), on the other hand, shows only one peak in both $\mathrm{D}_{\mathrm{m}}$ and $\sigma_{\mathrm{M}}$. The tropical environment may also be the reason that no larger drop mode was observed by the disdrometers or DPR.

Finally, a previously published method for separating stratiform and convective rain types was tested for the two events. The method is based on $N_{w}$ versus $D_{m}$ and has been tested using disdrometer data in several locations, e.g., [60-62], and against the texturebased method used in [63]. For the two events considered here, the DPR-based $N_{W}$ versus $\mathrm{D}_{\mathrm{m}}$ (again note considerably larger footprint) were used to identify regions of the two rain types. For the HSV event, the convective rain regions corresponded well with regions of high PIA from the matched scan. On the other hand, DPR data for Sally showed mostly stratiform rain during the overpass. This was confirmed by QVP constructed from NPOL radar for the event.

The two initial test cases show encouraging results for more informative and accurate DSD retrievals from DPR. Our retrieval method for DSD moments followed a procedure similar to previous work by Bringi et al. [31], using X-band ground-based polarimetric radar data. The third and the sixth moments had also been used for that study. It is likely that these are also applicable for the DPR based retrievals, but further investigations are needed. Another aspect to consider is the stability of $\mathrm{h}(\mathrm{x})$, specifically, whether having two sets of $\mathrm{h}(\mathrm{x})$, one for stratiform rain and one for convective rain would improve the overall retrievals. This will also be examined in the future.

The novelty of our method lies in the conceptual fact that the rain DSDs are better characterized in terms of moments rather than the DSD parameters governing the distributions. As mentioned earlier in the Introduction, DSD moments are far more informative about the microphysical processes involved in the observation regions. Given that the DPR is capable of providing vertical profiles of attenuation corrected radar reflectivities as well as specific attenuations at $\mathrm{Ku}$ and $\mathrm{Ka}$ bands, the height variations of the DSD moments will lead to better understanding of the dominant processes. One drawback to our method is that the Ka-band specific attenuation, as mentioned several times earlier, has not been made available as one of the 'official DPR products'. It is hoped that this will be included in the near future. The specific attenuation can also be used as one of the rain-rate estimators, as has been the base for S-band ground-based radars [68] as well as X-band ground-based radars [69].

Author Contributions: Conceptualization, M.T. and V.B.; Methodology, Investigation, and Formal Analysis, M.T. and V.B.; Data Curation, D.A.M. and M.T.W.; Writing-Original Draft Preparation, M.T. and V.B.; Writing-Review and Editing, P.N.G. and D.W.; Supervision, V.B., P.N.G. and D.W.; Resources, D.W. All authors have read and agreed to the published version of the manuscript. 
Funding: M.T. was funded by NASA's Precipitation Measurement Mission via Grant Award Number 80NSSC19K0676. V.B. was funded by NASA Atmospheric Dynamics program via Grant Award Number 80NSSC20K0893.

Data Availability Statement: Data can be made available upon request to any of the authors.

Acknowledgments: We wish to thank the four anonymous reviewers for their helpful comments.

Conflicts of Interest: The authors declare no conflict of interest. The funders had no role in the design of this study; in the collection, analyses, or interpretation of its data; in the writing of this manuscript, and in the decision to publish these results.

\section{Appendix A}

For the Huntsville event considered in Section 4.1, histograms of the retrieved DSD moments are shown in Figure A1 in this Appendix. The histograms were derived for all pixels (60) over and surrounding the disdrometer location. The latitude and longitude range are as follows:

- $\quad$ Latitude (deg) ... from 34.999 to 34.3029

- $\quad$ Longitude (deg) ... from -86.0023 to -86.9818

- $\quad$ Location of the disdrometers: $34.7245^{\circ}$ (lat) $-86.6398^{\circ}$ (lon)

The arrows in maroon color on top of each panel correspond to the range of values determined from the ground-based 3 min DSDs from 23:00 to 24:00 UTC, i.e., within $\pm 30 \mathrm{~min}$ period of the DPR overpass time of 23:31 UTC. Reasonable agreement is seen for the lower order moments, viz. $\mathrm{M}_{0}, \mathrm{M}_{1}$, and $\mathrm{M}_{2}$, as well as the higher-order moments, viz. $\mathrm{M}_{6}$ and $\mathrm{M}_{7}$. For those in the middle, i.e., $\mathrm{M}_{3}, \mathrm{M}_{4}$, and $\mathrm{M}_{5}$, there appears to be a slight overestimate of the values estimated from DPR. Overall, however, the range of DSD-based values lie well withing the range of the corresponding moments. The mean values from the DSD-based moments are provided above each panel.

As a further "sanity check", in Figure A2, we show (in green) the actual DSDs constructed from the retrieved from the DPR data from the abovementioned pixels. Overplotted in maroon are the DSD measurements from the 2DVD and MPS disdrometers over the same \pm 30 min period of the DPR overpass time of 23:31 UTC. The DSD measurements show less variability than the DPR-based DSDs, particularly at the larger sizes, but they mostly lie within the set of green curves. 

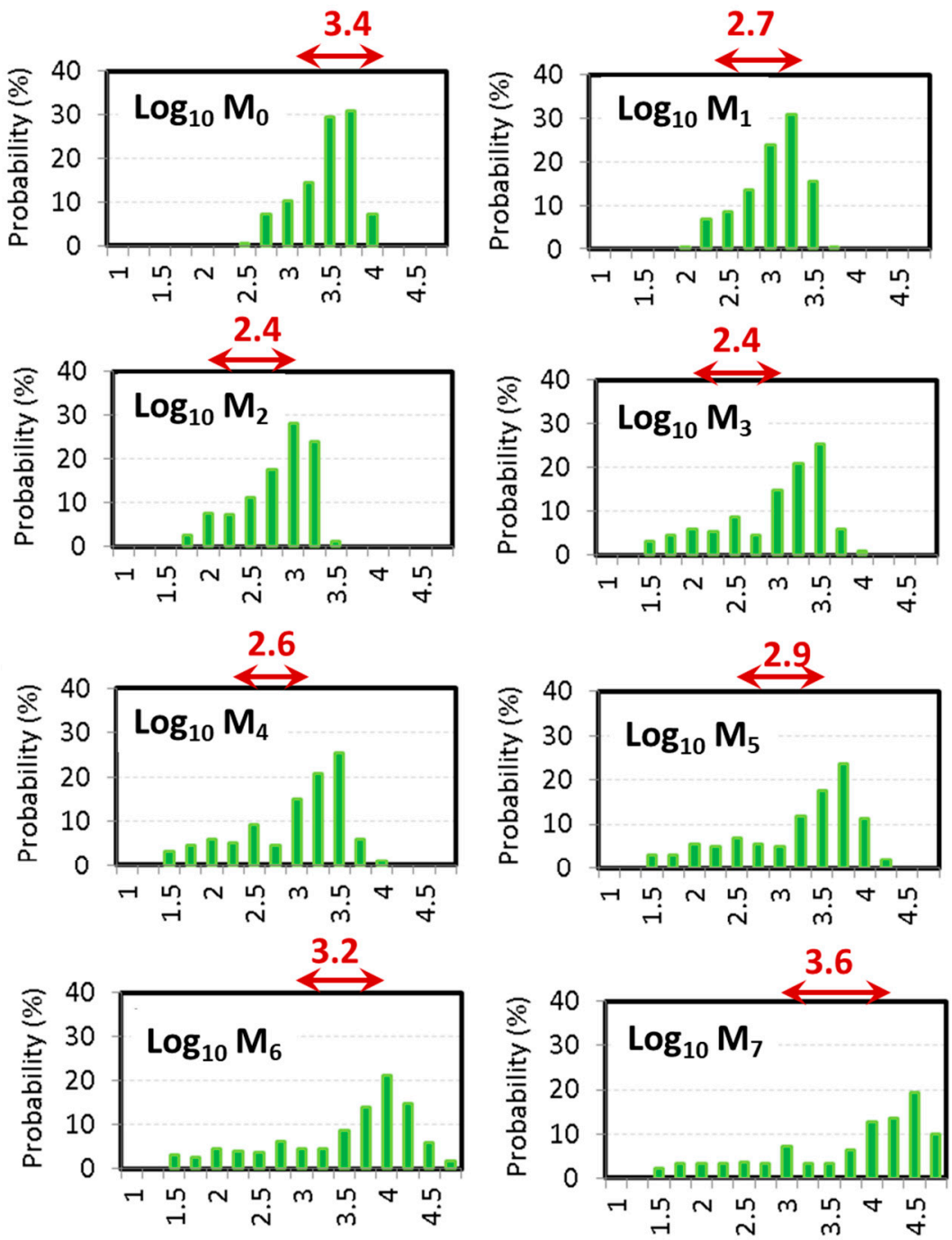

Figure A1. Histograms of moments (units are $\mathrm{mm}^{\mathrm{n}} / \mathrm{m}^{3}$ for the nth moment) shown in green derived from DPR data over and around the disdrometer site for the 11 April 2016 event in Huntsville (Figure 5). The maroon arrows represent those derived from the ground-based DSD measurements within $\pm 30 \mathrm{~min}$ period around the overpass time.

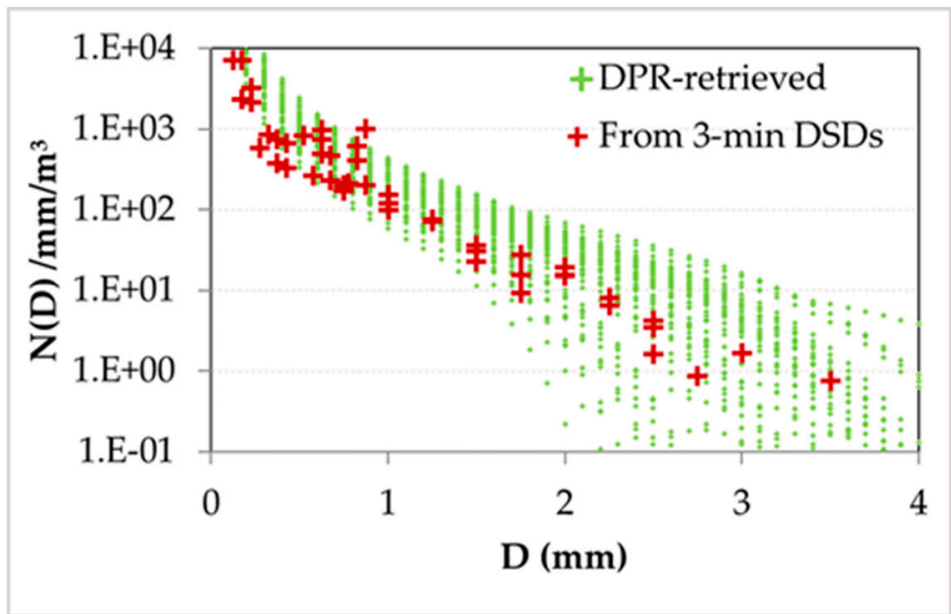

Figure A2. DSDs shown in green reconstructed from the moments in Figure A1 and those from the ground measurements in maroon. 


\section{References}

1. Hou, A.Y.; Kakar, R.K.; Neeck, S.; Azarbarzin, A.A.; Kummerow, C.D.; Kojima, M.; Oki, R.; Nakamura, K.; Iguchi, T. The Global Precipitation Measurement Mission. Bull. Am. Meteorol. Soc. 2014, 95, 701-722. [CrossRef]

2. Seto, S.; Iguchi, T.; Oki, T. The Basic Performance of a Precipitation Retrieval Algorithm for the Global Precipitation Measurement Mission's Single/Dual-Frequency Radar Measurements. IEEE Trans. Geosci. Remote Sens. 2013, 51, 5239-5251. [CrossRef]

3. Gao, J.; Tang, G.; Hong, Y. Similarities and Improvements of GPM Dual-Frequency Precipitation Radar (DPR) upon TRMM Precipitation Radar (PR) in Global Precipitation Rate Estimation, Type Classification and Vertical Profiling. Remote Sens. 2017, 9, 1142. [CrossRef]

4. Adirosi, E.; Montopoli, M.; Bracci, A.; Porcù, F.; Capozzi, V.; Annella, C.; Budillon, G.; Bucchignani, E.; Zollo, A.L.; Cazzuli, O.; et al. Validation of GPM Rainfall and Drop Size Distribution Products through Disdrometers in Italy. Remote Sens. 2021, 13, 2081. [CrossRef]

5. Testud, J.; Oury, S.; Black, R.A.; Amayenc, P.; Dou, X. The concept of "normalized" distribution to describe raindrop spectra: A tool for cloud physics and cloud remote sensing. J. Appl. Meteorol. 2001, 40, 1118-1140. [CrossRef]

6. Liao, L.; Meneghini, R. Physical Evaluation of GPM DPR Single- and Dual-Wavelength Algorithms. J. Atmos. Ocean. Technol. 2019, 36, 883-902. [CrossRef]

7. Iguchi, T.; Seto, S.; Meneghini, R.; Yoshida, N.; Awaka, J.; Le, M.; Chandrasekar, V.; Brodzik, S.; Kubota, T. GPM/DPR Level-2 Algorithm Theoretical Basis Document Version 6; NASA Goddard Space Flight Ceneter: Greenbelt, MA, USA, 2018.

8. Seto, S.; Iguchi, T.; Meneghini, R.; Awaka, J.; Kubota, T.; Masaki, T.; Takahashi, N. The Precipitation Rate Retrieval Algorithms for the GPM Dual-frequency Precipitation Radar. J. Meteorol. Soc. Jpn. Ser. II 2021, 99, 2021-011. [CrossRef]

9. Gatlin, P.N.; Petersen, W.A.; Pippitt, J.L.; Berendes, T.A.; Wolff, D.B.; Tokay, A. The GPM Validation Network and Evaluation of Satellite-Based Retrievals of the Rain Drop Size Distribution. Atmosphere 2020, 11, 1010. [CrossRef]

10. Radhakrishna, B.; Satheesh, S.K.; Rao, T.N.; Saikranthi, K.; Sunilkumar, K. Assessment of DSDs of GPM-DPR with ground-based disdrometer at seasonal scale over Gadanki, India. J. Geophys. Res. Atmos. 2016, 121, 11792-11802. [CrossRef]

11. Ryu, J.; Song, H.-J.; Sohn, B.-J.; Liu, C. Global Distribution of Three Types of Drop Size Distribution Representing Heavy Rainfall From GPM/DPR Measurements. Geophys. Res. Lett. 2021, 48, e2020GL090871. [CrossRef]

12. Hamada, A.; Takayabu, Y.N. Improvements in detection of light precipitation with the global precipitation measurement dual-frequency precipitation radar (GPM DPR). J. Atmos. Ocean. Technol. 2016, 33, 653-667. [CrossRef]

13. Tuttle, J.D.; Rinehart, R.E. Attenuation Correction in Dual-Wavelength Analyses. J. Appl. Meteorol. Climatol. 1983, $22,1914-1921$. [CrossRef]

14. Fujita, M. An algorithm for estimating rain rate by a dual-frequency radar. Radio Sci. 1983, 18, 697-708. [CrossRef]

15. Eccles, P.J. Comparison of Remote Measurements by Single- and Dual-Wavelength Meteorological Radars. IEEE Trans. Geosci. Electron. 1979, 17, 205-218. [CrossRef]

16. Walker, B.; Lamberth, L.S.; Stephens, J.J. Dual-Frequency Radar Observations of Precipitation. J. Appl. Meteorol. Climatol. 1964, 3, 430-438. [CrossRef]

17. Ellis, S.M.; Vivekanandan, J. Liquid water content estimates using simultaneous S and Ka band radar measurements. Radio Sci. 2011, 46, RS2021. [CrossRef]

18. Lee, G.; Zawadzki, I.; Szyrmer, W.; Sempere-Torres, D.; Uijlenhoet, R. A general approach to double-moment normalization of drop size distributions. J. Appl. Meteorol. 2004, 43, 264-281. [CrossRef]

19. Atlas, D.; Ulbrich, C.W. Path- and Area-Integrated Rainfall Measurement by Microwave Attenuation in the 1-3 cm Band. J. Appl. Meteorol. Climatol. 1977, 16, 1322-1331. [CrossRef]

20. Bringi, V.; Grecu, M.; Protat, A.; Thurai, M.; Klepp, C. Measurements of Rainfall Rate, Drop Size Distribution, and Variability at Middle and Higher Latitudes: Application to the Combined DPR-GMI Algorithm. Remote Sens. 2021, 13, 2412. [CrossRef]

21. Milbrandt, J.A.; McTaggart-Cowan, R. Sedimentation-Induced Errors in Bulk Microphysics Schemes. J. Atmos. Sci. 2010, 67, 3931-3948. [CrossRef]

22. Bryan, G.H.; Morrison, H. Sensitivity of a Simulated Squall Line to Horizontal Resolution and Parameterization of Microphysics. Mon. Weather Rev. 2012, 140, 202-225. [CrossRef]

23. Jameson, A.R. The Meteorological Parameterization of Specific Attenuation and Polarization Differential Phase Shift in Rain. J. Appl. Meteorol. 1993, 32, 1741-1750. Available online: http:/ /www.jstor.org/stable/44713974 (accessed on 19 November 2021). [CrossRef]

24. Milbrandt, J.A.; Yau, M.K. A Multi-moment Bulk Microphysics Parameterization. Part I: Analysis of the Role of the Spectral Shape Parameter. J. Atmos. Sci. 2005, 62, 3051-3064. [CrossRef]

25. Prat, O.P.; Barros, A.P.; Williams, C.R. an intercomparison of model simulations and VPR estimates of the vertical structure of warm stratiform rainfall during TWP-ICE. J. Appl. Meteorol. Climatol. 2008, 47, 2797-2815. [CrossRef]

26. Morrison, H.; Kumjian, M.R.; Martinkus, C.P.; Prat, O.P.; Van Lier-Walqui, M. A general N-moment normalization method for deriving raindrop size distribution scaling relationships. J. Appl. Meteorol. Climatol. 2019, 58, 247-267. [CrossRef]

27. Morrison, H.; van Lier-Walqui, M.; Kumjian, M.R.; Prat, O.P. A Bayesian Approach for Statistical-Physical Bulk Parameterization of Rain Microphysics. Part I: Scheme Description. J. Atmos. Sci. 2020, 77, 1019-1041. [CrossRef]

28. Szyrmer, W.; Laroche, S.; Zawadzki, I. A Microphysical Bulk Formulation Based on Scaling Normalization of the Particle Size Distribution. Part I: Description. J. Atmos. Sci. 2005, 62, 4206-4221. [CrossRef] 
29. Meneghini, R.; Liao, L. On the Equivalence of Dual-Wavelength and Dual-Polarization Equations for Estimation of the Raindrop Size Distribution. J. Atmos. Ocean. Technol. 2007, 24, 806-820. [CrossRef]

30. Raupach, T.H.; Berne, A. Retrieval of the raindrop size distribution from polarimetric radar data using double-moment normalization. Atmos. Meas. Tech. 2017, 10, 2573-2594. [CrossRef]

31. Bringi, V.; Mishra, K.V.; Thurai, M.; Kennedy, P.C.; Raupach, T.H. Retrieval of lower-order moments of the drop size distribution using CSU-CHILL X-band polarimetric radar: A case study. Atmos. Meas. Tech. 2020, 13, 4727-4750. [CrossRef]

32. Raupach, T.H.; Berne, A. Invariance of the double-moment normalized raindrop size distribution through 3D spatial displacement in stratiform rain. J. Appl. Meteorol. Climatol. 2017, 56, 1663-1680. [CrossRef]

33. Thurai, M.; Bringi, V.; Gatlin, P.N.; Petersen, W.A.; Wingo, M.T. Measurements and modeling of the full rain drop size distribution. Atmosphere 2019, 10, 39. [CrossRef]

34. Marshall, J.S.; Palmer, W.M.K. The distribution of raindrops with size. J. Meteorol. 1948, 5, 165-166. [CrossRef]

35. Ulbrich, C.W. Natural Variations in the Analytical Form of the Raindrop Size Distribution. J. Clim. Appl. Meteorol. 1983, 22, 1764-1775. [CrossRef]

36. Kozu, T.; Iguchi, T.; Shimomai, T.; Kashiwagi, N. Raindrop size distribution modeling from a statistical rain parameter relation and its application to the TRMM precipitation radar rain retrieval algorithm. J. Appl. Meteorol. Climatol. 2009, 48, 716-724. [CrossRef]

37. Williams, C.R.; Bringi, V.N.; Carey, L.D.; Chandrasekar, V.; Gatlin, P.N.; Haddad, Z.S.; Meneghini, R.; Munchak, S.J.; Nesbitt, S.W.; Petersen, W.A.; et al. Describing the Shape of Raindrop Size Distributions Using Uncorrelated Raindrop Mass Spectrum Parameters. J. Appl. Meteorol. Climatol. 2014, 53, 1282-1296. [CrossRef]

38. Mallet, C.; Barthes, L. Estimation of gamma raindrop size distribution parameters: Statistical fluctuations and estimation errors. J. Atmos. Ocean. Technol. 2009, 26, 1572-1584. [CrossRef]

39. Sekhon, R.; Srivastava, R.C. Doppler Radar Observations of Drop-Size Distributions in a Thunderstorm. J. Atmos. Sci. 1971, 28, 983-994. [CrossRef]

40. Bringi, V.N.; Chandrasekar, V. Polarimetric Doppler Weather Radar: Principles and Applications; Cambridge University Press: Cambridge, UK, 2001.

41. Ryzhkov, A.; Zrnic, D.S. Radar Polarimetry for Weather Observations; Springer: Cham, Switzerland, 2019.

42. Nakamura, K.; Iguchi, T. Dual-wavelength radar algorithm. In Measuring Precipitation from Space; Levizanni, V., Bauer, P., Turk, F.J., Eds.; Springer: Dordrecht, The Netherlands, 2007; pp. 225-234.

43. Skofronick-Jackson, G.; Kirschbaum, D.; Petersen, W.; Huffman, G.; Kidd, C.; Stocker, E.; Kakar, R. The Global Precipitation Measurement (GPM) mission's scientific achievements and societal contributions: Reviewing four years of advanced rain and snow observations. Q. J. R. Meteorol. Soc. 2018, 144, 27-48. [CrossRef] [PubMed]

44. Sempere-Torres, D.; Porrà, J.M.; Creutin, J.-D. Experimental evidence of a general description for raindrop size distribution properties. J. Geophys. Res. 1998, 103, 1785-1797. [CrossRef]

45. Illingworth, A.J.; Blackman, T.M. The Need to Represent Raindrop Size Spectra as Normalized Gamma Distributions for the Interpretation of Polarization Radar Observations. J. Appl. Meteorol. 2002, 41, 286-297. [CrossRef]

46. Yu, N.; Delrieu, G.; Boudevillain, B.; Hazenberg, P.; Uijlenhoet, R. Unified Formulation of Single- and Multimoment Normalizations of the Raindrop Size Distribution Based on the Gamma Probability Density Function. J. Appl. Meteorol. Climatol. 2014, 53, 166-179. Available online: http:/ / www.jstor.org/stable/26175953 (accessed on 18 November 2021). [CrossRef]

47. Auf der Maur, A.N. Statistical tools for drop size distributions: Moments and generalized gamma. J. Atmos. Sci. 2001, 58, 407-418. [CrossRef]

48. Baumgardner, D.; Kok, G.; Dawson, W.; O’Connor, D.; Newton, R. A new ground-based precipitation spectrometer: The Meteorological Particle Sensor (MPS). In Proceedings of the 11th Conference on Cloud Physics, Ogden, UT, USA, 2-3 June 2002; p. 8.6.

49. Schoenhuber, M.; Lammer, G.; Randeu, W.L. One decade of imaging precipitation measurement by 2D-video-distrometer. Adv. Geosci. 2007, 10, 85-90. [CrossRef]

50. Schönhuber, M.; Lammer, G.; Randeu, W.L. The 2D-Video-Distrometer. In Precipitation: Advances in Measurement, Estimation and Prediction; Michaelides, S., Ed.; Springer: Berlin/Heidelberg, Germany, 2008; pp. 3-31, ISBN 978-3-540-77654-3.

51. Rasmussen, R.; Baker, B.; Kochendorfer, J.; Meyers, T.; Landolt, S.; Fischer, A.P.; Black, J.; Thériault, J.M.; Kucera, P.; Gochis, D.; et al. How Well Are We Measuring Snow: The NOAA/FAA/NCAR Winter Precipitation Test Bed. Bull. Am. Meteorol. Soc. 2012, 93, 811-829. [CrossRef]

52. Raupach, T.H.; Thurai, M.; Bringi, V.N.; Berne, A. Reconstructing the Drizzle Mode of the Raindrop Size Distribution Using Double-Moment Normalization. J. Appl. Meteorol. 2019, 58, 145-164. [CrossRef]

53. Thurai, M.; Gatlin, P.N.; Bringi, V.N.; Petersen, W.A.; Notaros, B.; Carey, L.D.; Kennedy, P. Towards completing the rain drop size spectrum: Case studies involving 2D-video disdrometer, droplet spectrometer, and polarimetric radar measurements. J. Appl. Meteorol. Climatol. 2017, 56, 877-896. [CrossRef]

54. Bringi, V.; Seifert, A.; Wu, W.; Thurai, M.; Huang, G.-J.; Siewert, C. Hurricane Dorian Outer Rain Band Observations and 1D Particle Model Simulations: A Case Study. Atmosphere 2020, 11, 879. [CrossRef]

55. Mishchenko, M.I.; Travis, L.D.; Mackowski, D.W. T-matrix computations of light scattering by nonspherical particles: A review. J. Quant. Spectrosc. Radiat. Transf. 1996, 55, 535-575. [CrossRef] 
56. Thurai, M.; Bringi, V.N.; Wolff, D.B.; Marks, D.A.; Pabla, C.S. Drop Size Distribution Measurements in Outer Rainbands of Hurricane Dorian at the NASA Wallops Precipitation-Research Facility. Atmosphere 2020, 11, 578. [CrossRef]

57. Brown, B.R.; Bell, M.M.; Frambach, A.J. Validation of simulated hurricane drop size distributions using polarimetric radar. Geophys. Res. Lett. 2016, 43, 910-917. [CrossRef]

58. Wolff, D.B.; Petersen, W.A.; Tokay, A.; Marks, D.A.; Pippitt, J.L. Assessing Dual-Polarization Radar Estimates of Extreme Rainfall during Hurricane Harvey. J. Atmos. Ocean. Technol. 2019, 36, 2501-2520. [CrossRef]

59. Ryzhkov, A.V.; Zhang, P.; Reeves, H.; Kumjian, M.; Tschallener, T.; Tromel, S.; Simmer, C. Quasi-Vertical Profiles-A new way to look at polarimetric radar data. J. Atmos. Ocean. Technol. 2016, 33, 551-562. [CrossRef]

60. Bringi, V.N.; Williams, C.R.; Thurai, M.; May, P.T. Using dual-polarized radar and dual-frequency profiler for DSD characterization: A case study from Darwin, Australia. J. Atmos. Ocean. Technol. 2009, 26, 2107-2122. [CrossRef]

61. Thurai, M.; Gatlin, P.N.; Bringi, V.N. Separating stratiform and convective rain types based on the drop size distribution characteristics using 2D video disdrometer data. Atmos. Res. 2016, 169 Pt B, 416-423. [CrossRef]

62. Thurai, M.; Bringi, V.; Wolff, D.; Marks, D.; Pabla, C. Testing the Drop-Size Distribution-Based Separation of Stratiform and Convective Rain Using Radar and Disdrometer Data from a Mid-Latitude Coastal Region. Atmosphere 2021, 12, 392. [CrossRef]

63. Steiner, M.; Houze, R.A.; Yuter, S.E. Climatological Characterization of Three-Dimensional Storm Structure from Operational Radar and Rain Gauge Data. J. Appl. Meteor. 1995, 34, 1978-2007. [CrossRef]

64. Thurai, M.; Wolff, D.; Marks, D.; Pabla, C.; Bringi, V. Separation of Stratiform and Convective Rain Types Using Data from an S-Band Polarimetric Radar: A Case Study Comparing Two Different Methods. Environ. Sci. Proc. 2021, 8, 1. [CrossRef]

65. Thurai, M.; Bringi, V.N.; May, P.T. CPOL radar-derived drop size distribution statistics of stratiform and convective rain for two regimes in Darwin, Australia. J. Atmos. Ocean. Technol. 2010, 27, 932-942. [CrossRef]

66. Penide, G.; Kumar, V.; Protat, A.; May, P.T. Statistics of drop size distribution parameters and rain rates for stratiform and convective precipitation during the north Australian wet season. Mon. Weather Rev. 2013, 141, 3222-3237. [CrossRef]

67. Haddad, Z.S.; Short, D.A.; Durden, S.L.; Im, E.; Hensley, S.; Grable, M.B.; Black, R.A. A new parametrization of the rain drop size distribution. IEEE Trans. Geosci. Remote Sens. 1997, 35, 532-539. [CrossRef]

68. Ryzhkov, A.V.; Diederich, M.; Zhang, P.; Simmer, C. Potential utilization of specific attenuation for rainfall estimation, mitigation of partial beam blockage, and radar networking. J. Atmos. Ocean. Technol. 2014, 31, 599-619. [CrossRef]

69. Thurai, M.; Mishra, K.V.; Bringi, V.N.; Krajewski, W. Initial Results of a New Composite-Weighted Algorithm for Dual-Polarized X-Band Rainfall Estimation. J. Hydrometeorol. 2017, 18, 1081-1100. [CrossRef] 